\title{
Destabilizing Racial Classifications Based on Insights Gleaned from Trademark Law
}

\begin{abstract}
Alex M. Johnson Jr. $\dagger$
As I stepped onto the bus one early morning, the driver, a young black man, said I was a dime short. I was positive I had deposited the proper fare. I did a slight burn, though concealed. To avoid an unpleasant exchange, I fished out another dime and dropped it into the box. My annoyance, trivial though the matter was, stayed with me for the rest of the trip. Oh, I understood the man. Of course. I know the history of his people's bondage. It was his turn-a show of power, if only in a small way. If that's how it is, that's how it is. Oh, well.

As I was about to disembark, I saw a dime on the floor. My dime. I held it up to him. "You were right." He was too busy driving to respond. In alighting, I waved: "Take it easy." "You, too," he replied. I've a hunch he'd been through something like this before.

In this one man, I had seen the whole race. In his behavior (especially before my discovery of the dime), I saw all African Americans. During the trips I had conducted a silent seminar on ontogeny recapitulating [phylogeny]. ${ }^{1}$
\end{abstract}

Copyright @ 1996 California Law Review, Inc.

$\dagger$ Daniel and Mary Loughran Professor of Law, University of Virginia School of Law; Vice Provost for Faculty Recruitment and Retention, University of Virginia. B.A., 1975, Claremont Men's College; J.D., 1978, U.C.L.A. School of Law. John Monahan graciously assisted me in locating and understanding the psychological and psychobiological literature essential to the preparation of the Article. I also benefited from conversations about this topic with my colleagues, Mary Anne Case and George Triantis. 1 also thank my research assistants, Barb Parisi and Sara Dingfelder, who provided invaluable assistance in the completion of this Article. Lastly, I wish to thank the participants in the workshop at the University of Iowa College of Law where an earlier version of this paper was presented.

1. Studs Terket, Race: How Blacks and Whites Think and Feel about the AMERICAN OBSESSION 6 (1992). 


\section{INTRODUCTION}

The construct of race in American society raises many puzzling questions. First and foremost is the continued persistence of racism. Racism is illogical in light of evidence that one's skin color, bone structure, and hair texture ${ }^{2}$ do not correlate with any personal attribute or characteristic, such as intelligence ${ }^{3}$, propensity for violent acts ${ }^{4}$, athletic capabilities ${ }^{5}$, or other important attributes that could and should be relied on by others in either awarding entitlements or making subjective, normative judgments about the worth of individuals and the skills that they possess.

One intractable puzzle that has intrigued me concerns the persistence of a dichotomous racial classification in American society. When one examines how race is constructed and defined in society, it is startling to note that racial categories traditionally have been divided into two camps: white and black. ${ }^{6}$ This dichotomy began early in

2. Anthony Appiah characterizes these observable physical characteristics as the "grosser morphology" of an individual. Kwame A. APPIAH, IN MY FATHER's HousE: AFRICA IN TIE Philosophy of Culture 34-38 (1992). The term "phenotype" also is used to indicate the amalgamation of observable, visible traits possessed by an individual. See JAmes C. King, The BiologY OF RACE 20 (rev. ed. 1981).

3. See Stephen J. Gould, The Mismeasure of Man 273-74 (1981). Compare the odious claim made in Richard J. Hermstein \& Charles Murray, The Bell Curve: INTELljgence aND Class STRUCTURE IN AMRRICAN LIFE (1994) that blacks have, on average, significantly lower cognitive ability or intelligence than similarly situated whites. Consonant with the thesis of this Article, any such argument must be premised on defensible and definable racial classifications in which whites can genetically be differentiated from blacks. See NEw Repunlic, Oct. 3I, 1994, at 925 (various authors critiquing the Murray-Hermstein theory).

4. In a related vein, see Douglas S. Massey, Getting Away with Murder: Segregation and Violent Crime in Urban America, 143 U. PA. L. REv. 1203, 1210-17 (1995) (arguing that the violence perpetuated in the inner-city ghettos is largely a product of segregation and poverty rather than any innate propensity for violence).

5. For a discussion of why blacks disproportionately choose to play sports, see Alex M. Johnson, Jr., Hoop Dreams: Rational Behavior, Meritocratic Standards and Affirmative Action"Why Shaquille Chooses to Play Basketball or Tell Jokes Instead of Going to Law School" (Jan. 1996) (unpublished manuscript, on file with author) (arguing that it is economically rational for individual blacks to place an emphasis on attaining a professional sports career given the underinvestment in luman capital created and caused by the historical effects of racism).

6. When I use the term "black," I am referring to an individual's racial designation under the "one drop of blood" rule, which provides that an individual with any level of black ancestry, even as little as "one drop," must be classified as black. For a historical genesis of the "one drop of blood" rule, see Paul Finkelman, The Crime of Color, 67 Tul. L. Rev. 2063, 2110 (1993).

There is currently a trend to refer to individuals who used to be referred to as blacks as African Americans. This trend has spurred a debate, waged largely in the footnotes of sevcral articles, conceruing the appropriateness of both terms. See, e.g., Neil Gotanda, A Critique of "Our Constitution Is Color-Blind," 44 STAN. L. REv. 1, 4 n.12 (1991).

Recently, for example, Cheryl Harris joined Professor Crenshaw in using the term "Black," explaining: "I use the term 'Black' throughout the paper for the reasons articulated by Professor Kimberle Crenshaw. I share her view that 'Blacks, like Asians, Latinos, and other 'minorities,' constitute a specific cultural group and, as such, require denotation as a proper noun."' Cheryl Harris, Whiteness as Property, 106 HARv. L. Rev. 1707, 1710 n.3 (1993) (quoting Kimberle W. 
American history, with the advent of slavery. Under the "one drop of blood" rule, which provided that any individual with at least one black ancestor was assigned the status of black, individuals were categorized as either one hundred percent white or black-there was no in-between for individuals of mixed ancestry. ${ }^{\text {? }}$

In particular, unlike other societies, current American society refuses to recognize a mixed-race or mulatto category that encompasses those individuals who are the products of a "mixed-union or marriage" between a white and a black, choosing instead to classify such individuals as black. ${ }^{8}$ This is true despite the fact that mixed-race offspring will inevitably increase in accordance with the demonstrated increase of interracial unions or marriages. In fact, "[o]fficials expect complaints [by progeny of mixed-racial unions regarding their classification on Census Forms as 'other'] to become more frequent in the coming years as the number of interracial marriages rises."

Crenshaw, Race, Reform, and Retrenchment: Transformation and Legitimation in Antidiscrimination Law, 101 HARv. L. Rev. 1331, 1332 n.2 (1988)). Nikki Giovanni states more directly:

I am a black American. Period. The rest is of no particular interest to me. AfroAmerican, African American, whatever. I believe that if I remain a black American I force all others to become and claim their other Americanisms. They are white Americans, Irish-Americans, Jewish-Americans, or whatever hyphens they would like to use. The noun is "black"; American is the adjective.

Nikki Giovanni, Black Is the Noun, in LuRE AND LOATHING: ESSAYS ON RACE, IDENTITY, AND THE Ambivalence of Assimilation 113, 122 (Gerald Early ed., 1993) [hereinafter LuRE AND LOATHING].

It is interesting to note that in the passage quoted above Kimberle Crenshaw referred to "Blacks" as constituting "a specific cultural group" rather than a race. Likewise encapsulated within Nikki Giovanni's definition of the noun "black" is a comparative baseline pursuant to which other ethnic and racial groups are contrasted. The purpose of this Article is largely to identify and disentangle the conflation of race and ethnicity.

Thus, it is important to note that, although I use the term "African American" later in this Article, I redefine it as an ethnic rather than a racial classification. The ethnic elassification "African American," as I define it, consists of individuals who may or may not be viewed as either phenotypically black or black pursuant to the "one drop of blood" rule. See infra text accompanying notes 160-61.

7. See Finkelman, supra note 6 , at 2110.

8. The Census Bureau currently utilizes four specific racial categories in addition to the generic "other" category: white, black, Asian-Pacific Islander, and American-Indian-Alaskan native. Steven A. Holmes, U.S. Urged to Reflect Wider Diversity in Racial and Ethnic Classifications, N.Y. TIMES, July 8, 1994, at A18 (national ed.). The American legal system also lacks intermediate or "mixed-race" classifications. Gotanda, supra note 6, at 25. See also MAGNus MoRnER, RACE MiXTURE IN THE History OF LATIN AMERICA 58 (1967) (including a table that ranks 16 raciaI categories denoting ancestry in New Spain (Mexico) during the eighteenth century); THOMAS Sowell, The Economics AND Politics of RaCe 95-107 (1983) (comparing the classification system in the United States to that of other countries). For further discussion of the American classification system, see infra notes $27-33,45,48-55$ and accompanying text.

9. Holmes, supra note 8 , at A18 (reporting that the percentage of interracial unions increased from $.4 \%$ of all marriages in 1960 to $2.2 \%$ in 1992, raising concerns about the current census classification system). The increasing number of mixed-race offspring beties the once-accepted proposition, used to support anti-miscegenation statutes, that certain offspring of mixed-race couples 
However, as long as there are visible traces of melanin in a person's skin allowing an observer to conclude that an ancestor of the individual was black, ${ }^{10}$, the individual will be identified and categorized racially as a black person under the current classification scheme."

This Article attempts to explain the continued existence of a dichotomous racial scheme in American society. I maintain that this phenomena can be explained in part by the concept of "whiteness" as a property right. ${ }^{12}$ However, the fact that "whiteness" is protected as a valuable property right in this society does not explain why other racial classifications or categories have not developed to identify those who are the products of mixed-race unions. ${ }^{13}$

I argue that the wholesale rejection of multi-racial categories in American society can be explained by the fact that racial classifications function most effectively as a vehicle for discrimination and empowerment when they are manipulated to maintain a duality that has the effect of entrenching the notion of "otherness." This notion of otherness is established by using a baseline of white racial purity. As a result, I contend that race and racism in American society will never be reduced or eliminated until the manuer in which race is categorized is radically altered to take into account the products of mixed-union (miscegenetic) mating in a way that recognizes their unique ethnicity and heritage.

By defining our racial categories as simply black and white, with white viewed as normal or good and black viewed as different or bad, whites and blacks have relied on ostensibly stable racial categories that have the effect of benefiting whites at the expense of persons of color and blacks in particular. By that I mean that whites have been able to relegate all persons of color to subordinate status by reference to what they are not: white. Whiteness then becomes the defining, driving category by which others are measured. Moreover, since whiteness is characterized as the absence of black or "blackness," white purity is maintained when whites selectively reproduce with other whites. This

could not produce children. James Trosino, American Wedding: Same-Sex Marriage and the Miscegenation Analogy, 73 B.U. L. REv. 93, 103-04 (1993).

10. For further discussion of this method of categorization, see infra notes $30-33$ and accompanying text.

11. The absence of melanin in a person's skin does not mean that the person has no black ancestors. Indeed, many individuals consider themselves black but, due to their light pigmentation, are viewed as white and therefore may "pass" for white in American society. For a discussion of the phenomenon of "passing," see Harris, supra note 6, at 1710-15, 1765-66, and infra notes 125-26 and accompanying text.

12. See Harris, supra note 6 ; infra notes $99-108$ and accompanying text.

13. Elsewhere, mixed-race children are treated quite differently depending upon the society. See infra notes 34-46 and accompanying text. The "one drop of blood" rule that automatically classifies the offspring of a black and a white as black seems to be unique to the United States. See infra notes 25-27 and accompanying text. 
selective mating with the presumptively superior race has the effect of maintaining racial identity and enforcing self-imposed segregation so that whites socialize and interact only with other whites.

By focusing on blacks and the black/white dichotomy, I do not mean to diminish or ignore the same duality as it applies to other classifications based on what I will loosely term ethnicity or race. Unquestionably, the same duality or dichotomous classification scheme exists for other races or ethnic classifications. I choose to focus exclusively on the black/white dichotomy in this Article, not because it is unique to racism as it currently exists in Anerican society, but rather because it formed the precursor for all white/non-white dichotomies that currently exist in American society. ${ }^{14}$

In order to deconstruct this harmful racial dichotomy, I contend that society should embrace, as a transitory vehicle, multiple racial categories that expressly recognize and acknowledge products of mixed-race unions as distinct from both blacks and whites. I assert that this will have the effect of creating a type of "shade confusion" which will eventually destroy the black/white dichotomy that currently exists, ultimately reducing race to a meaningless category, as it should be. I further maintain that positive ethnic categories, which unite individuals on the basis of shared history and values rather than appearances, will rise to fill the void created by the deconstruction of race. Yet, the attainment of this color-blind society cannot and will not occur if the current topology of race continues to exist. ${ }^{15}$

I outline the thesis of this Article in three distinct parts. Part I begins by providing a brief historical overview of the development of the current racial topology and focuses on why American society is divided largely into two camps: black and white. The primary focus is comparative. As detailed in Part $I$, the startling duality of the racial classification scheme that exists in the United States is made even more surprising by the awareness that other societies have multiple racial categories. In this comparative section, other multi-racial societies such as Brazil and South Africa are analyzed to determine how their racial classification schemes differ from the predominantly biracial classification scheme that continues to exist in the United States.

14. For a discussion of Hispanics and their unique categorization, see Part 1II.A.1, infra.

15. Although recent Supreme Court opinions such as Adarand Constructors, Inc. v. Pena, II5 S. Ct. 2097 (1995), Missouri v. Jenkins, 115 S. C. 2038 (1995), and Millcr v. Johnson, 115 S. Ct. 2475 (1995), seem to be premised on an assuniption that we currently live in a color-blind society in which race is no longer relevant, see Joan Biskupic, Court's Conservatives Make Presence Felt, WaSH. PosT, July 2, 1995, at A1, A17, the baseline from which this Article proceeds is that race and racism are still pervasive factors in American society and do indeed constitute the "American Obsession." See also TERKEL, supra note 1. 
Most importantly, however, by focusing inward, Part I details how the integrationist strategy internalized and adopted by blacks to achieve equality has had a detrimental effect on the economic and cultural development of the black community. Blacks have internalized the values of whites and white society in developing their own subculture of race. This internalization of white American values reinforces the existing dichotomy that polarizes individuals and exacerbates the racial issue in American society. By imposing their own scheme of "Color Consciousness,"16 which uses whiteness as a metric of worth and validity, blacks have internalized their subordinated position and unintentionally helped solidify the notion of whiteness as a property right.

Part $I$ of the Article demonstrates that the current racial topology can and will be eliminated if multi-racial categories are recognized and allowed to flourish. To prove my thesis, I explore the efficiency rationale for trademark law and explicate its analogue to racial identification and topology. In effect, I view racial identification or typecasting and the designation of one as black, Asian, Hispanic, or any other non-white racial categorization as a "mark" that has heretofore been protected by whites im order to protect their property right in that very same whiteness. By destroying the exclusivity and meaning of the racial mark, I hope to make generic any sort of racial identification. What I hope to accomplish is the equivalent of "shade confusion," in which racial identification based on visible phenotypes is obscured or eradicated. ${ }^{17}$ In the short run, this deconstruction of race may have a splintering effect on people of color and especially blacks. In the long run, however, I hope to demonstrate that any splintering effect will also have a spillover effect on the definition of "white" and will destroy the dichotomy that has driven race relations in this country for centuries.

To demonstrate the benefits created by shade confusion and by having a multiplicity of racial categories premised predominantly on an ethnic rather than a binary racial classification, the focus of Part III shifts to another racial/ethnic group, Hispanics, who occupy a relatively unique position in the racial hierarchy of the United States. As currently constructed, the term Hispanic is an ethnic rubric under which people of all racial types are classified. Unlike whites or blacks, Hispanic as a racial category is meaningless because an Hispanic can be of any race. Hence, being identified as an Hispanic imparts no racial identification (and, relatedly, no racial stereotypes). ${ }^{18}$ To a large extent,

16. See infra text accompanying notes $56-65$ for a definition and discussion of Color Consciousness.

17. For further discussion and definition of "shade confusion," see infra notes $148-53$ and accompanying text.

18. By this I mean that in many parts of the United States, with the Southwest as the notable exception, if one is told that an individual who is not present and visible is an Hispanic, the individual 
the designation Hispanic represents a fluid and rather large ethnic group consisting of many subgroups or types. ${ }^{19}$ These subgroups or types are linked rather loosely to each other, and they are grouped not by reference to a racial division, but by a common language group or heritage. ${ }^{20}$

A lesson is learned, and a paradigm is embraced, that originates from the treatment of Hispanics as an ethnic group. As a result, in Part III I contend that the ethnic group of "blackness" or African American should develop to fill the void created by the destabilization of racial categories. ${ }^{21}$ Given the "black experience" and this country's history of forced (de jure) segregation and subsequent de facto segregation, African Americans have developed as a people or ethnic community into "a nation within a nation" with their own unique ethnic identity. Hence, I conclude that maintaining African American as an ethnic definition, while destabilizing racial classifications, will have a positive and rewarding effect.

I address in Part III the related contention that I have simply shifted the construct of black or "blackness" from a racial to an ethnic construct with no visible or tangible benefits. I reject that contention by demonstrating that the manner in which we view and respect ethnicity is

so advised cannot, with any degree of certainty, assign the Hispanic to a racial category and rely on the concomitant stereotypes that ensue from such racial identification. This is so because an Hispanic can be of any race.

However, the identification of the individual as an Hispanic may cause the individual being told to assign to the Hispanic being identified thusly negative stereotypes associated with the ethnicity of Hispanism, for example, laziness, large famihes, etc. See, e.g., Tom W. Smith, Ethnic Images in the United States, Polling ReP., May 27, 1991, at 1 (finding that, although being identified as ethnically Hispanic carries fewer negative stereotypes than being identified racially black, there is more than adequate evidence that there are negative stereotypes associated with the Hispanic ethnic classification). This sort of stereotypical assignation based on ethnicity is different from the stereotypes that fiow from racial identification, in that ethnic classifications cut across racial lines, which themselves are largely based on phenotype or phenotypical identification. In this respect, being identified as ethnically Hispanic may have the same disabling characteristics as being identified racially as black. Thus, to some extent, ethnicity, as it applies to Hispanics, is being conflated with race and may explain the move by some to change the ethnic identification of Hispanic to a racial identification on the 2000 Census. For further discussion of this issue, see infra note 178 and accompanying text.

19.

In the famous words of Jose Vasconcelos, the Mexican philosopher, it is in Latin America that a new race will come into being, "made of the treasury of all the previous races, the final race, the cosmic race." ... No part of the world has ever witnessed such a gigantic mixing of races as the one that has been taking plaee in Latin America and the Caribbean since 1492. In fact, it is impossible to determine the racial status of most Latin Americans without a genetic and anthropometric investigation.

MORNeR, supra note 8, at 1 (citing José Vasconcelos, Raza Cósmica (1925)).

20. Because the term is broadly defined, many people are able to claim Hispanic origin. The only common denominator appears to be a connection with a Spanish-speaking ancestor.

21. This Article defines the ethnic classification of African American in direct opposition to the current racial category of black or blackness. A more detailed discussion of the dichotomy between ethnicity and race occurs infra at text accompanying notes 164-82. 
positive when compared to race. In other words, in a perfect world, neither race nor ethnicity would exist as a vehicle to brand and label people as "others." However, the positive aspects of ethnicity, the "nomos" created by ethnicity, would also be lost. ${ }^{22}$ As we do not reside in a perfect world, I believe the positive attributes of ethnicity should be embraced and the social construction of race rejected because it is much easier to mask one's ethnicity and, if necessary, reconstruct one's ethnic identity to avoid the costly effects of being labeled "other" or disapprovingly different. Consequently, there is an illusory feature of ethnicity that is not valid with respect to race; ethnicity can be manipulated to extract positive benefits while marginalizing and reducing the negative consequences or costs.

In addition, in Part III I address the political concerns stemming from my thesis. I disagree with others who believe that blacks need to maintain the current state of affairs as it pertains to racial topology in order to harness and maintain their political strength in this society. I conclude that although that particular goal may be accomplished in the short term via the maintenance of the current racial topology, its maintenance ultimately will result in a detrimental, long-term cost. Instead, I advocate the express adoption of multi-racial categories in order to beget the long-term benefit of eliminating race and racism in this society. In the short term, alliances must be made across these multi-racial boundaries in order to maintain and increase political strength. I deem this short-term strategy of maintaining and perfecting alliances to be quite attainable given the commonality of interests that cut across multi-racial lines.

I recognize that the short-term effects of my proposal may be to weaken the univocal voice of people who have heretofore been characterized ethnically as African Americans (and before that racially as "black"). Such a cost, however, is necessary, due to the long-term benefits that will be realized by destabilizing the dichotomy of race. Moreover, a new political strategy is suggested that rejects racial essentialization and constructs alliances built upon historical facts, not the color of one's skin.

Therefore, Part III concludes by demonstrating that destabilizing racial identification as a result of lessons learned from trademark law will result in the creation of a "black" ethnic group, African

22. For an extended discussion and definition of "nomos," see Alex M. Johnson, Jr., Bid Whist, Tonk, and United States v. Fordiee: Why Integrationism Fails African-Americans Again, 81 CALIF. L. Rev. 1401, 1419-20 (1993). Robert Cover defines "nomos" as a community's "normative universe," the "commonalities of meaning that make continued normative activity possible." Robert M. Cover, The Supreme Court, 1982 Term-Foreword: Nomos and Narrative, 97 HARv. L. REv. 4, 14 (1983). 
Americans..$^{23}$ This beneficial creation will mirror the treatment of Hispanics as an ethnic group. Indeed, recent attempts to racialize Hispanics by creating a racial group designated "Hispanic" are addressed and rebuffed as the antipode of the thesis presented herein to destabilize racial classification. Instead of creating discrete racial groups that are identified via pictorial prototypes, such groupings must be obliterated, ethnicity must supplant race, and visual categorizations must be replaced by categorizations founded or based upon information communicated to the party undertaking the categorization.

\section{I}

\section{UNDERSTANDING THE CONTINUEd EXISTENCE OF A} RaCial Dichotomy IN AMERICAN SOCIETY

Unlike other societies that historically have recognized a multitude of racial classifications, America has consistently maintained a white/black dichotomy in the area of race relations. Through the use of legal constructs, such as the "one drop of blood" rule, our society has successfully maintained the ideal of white racial purity, relegating all black and mixed-union individuals to a subordinate status. In this section, I trace the historical development of the American racial dichotomy, comparing it to classifications employed in other countries. Additionally, I analyze the black community's response to such racial classifications. In particular, I explain how many blacks have embraced and perpetuated the racial dichotomy by endorsing the principles of "Color Consciousness," thus becoming the vehicles for their own oppression.

\section{A. A Comparative Analysis of Racial Classifications in America and Other Societies}

The social construction of race, and its untoward progenyracism - can obviously be traced to the existence of slavery in early American society. What is not as well known, however, is how the confluence of slavery and the democratic ideals upon which this country was founded converged to produce a species of racism and racial characterization that may be unique in civilized history. As Thomas Sowell explained:

American democratic ideals in fact made it morally necessary to justify the treatment of blacks by a racist ideology more sweeping than anything found in less democratic societies, such as those of Latin America or even South Africa. The morality of

23. As noted previously and discussed in Part III, the African American ethnic group is composed of individuals of all racial types who are hinked not only by race, but rather by a common heritage, history, and nomos which establishes their uniqueness and common bond. 
slavery had seldom been a serious issue in most slave societies in history, but because of the American ideal of freedom, the institution of slavery was an anachronism embroiled in controversy from the outset. ${ }^{24}$

The tension created by these two conflicting tenets-enslaving one group of human beings based on the color of their skin and their geographic origin, while proclaiming that all men are created equalcreated a negative view of blacks that continues to affect race relations today.

The racist ideology used to justify slavery in the face of democratic ideals had a unique impact on miscegenetic relationships in early American history and on the products of such relationships-mulattoes.

In early colonial America, ... mulattoes were often the offspring of black men and white women-a relationship viewed far less tolerantly. Moreover, mulattoes in colonial America "were usually the sons and daughters of lower-class whites rather than of rich planters and their slave concubines, as was generally the case in other New World slave societies." American mulattoes were not from an upper-class culture to the same extent as mulattoes elsewhere. There was less cultural difference, as well as no legal distinction, between American Negroes with differing amounts of white ancestry. ${ }^{25}$

In addition to democratic concerns, there were also economic reasons why mixed-race individuals were not treated differently from freed pure blacks in early American colonial society. Unlike other societies in which mulattoes filled a niche by providing skilled manual labor, the presence of a large white working class consigned all blacks, pure and mixed, to menial labor. ${ }^{26}$ Hence, mulattoes toiled alongside pure blacks and were considered by whites to be no different than their pure black counterparts.

The confluence of racism and sexism, forged by the unique role that slavery played in the political and economic development of America, eventually led to the creation of the "one drop of blood" rule. Pursuant to this rule, all offspring of an interracial union between a black and a white were relegated to the status of black, ${ }^{27}$ thus allowing white slave owners to preserve the balance of power over the slave community. As F. James Davis noted:

American slave owners wanted to keep all racially mixed children born to slave women under their control, for economic and

24. SoweLL, supra note 8 , at 121 (footnote omitted).

25. Id. at 122 (quoting GEORge M. FredrICKSON, White Supremacy 102-03 (1981)) (footnotes omitted).

26. Id. at 122-23.

27. See Finkelman, supra note 6 , at 2110 . 
sexual gains, and that to define such children as anythiug other than black becaine a major threat to the entire system. It was intolerable for white women to have mixed children, so the onedrop rule favored the sexual freedom of white males, protecting the double standard of sexual morality as well as slavery. After the Civil War, because of the great fear of miscegenation involving Southern white women, mulattoes were increasingly alienated from whites. Instead of developing into a status group between black and white,... the lighter mulattoes provided the foundation for the upper-upper class in the American black community. The whites had left no alternative-a person either passed as white or remained black. ${ }^{28}$

The "one drop of blood" rule exists in stark contrast to the classification schemes of many societies that choose to differentiate between their mixed-race or mulatto offspring and their pure black counterparts. These societies evidence a completely different construction of race than that found in America. For example, generally speaking, the fact that there were relatively few "pure" whites in South America and the Caribbean led to different treatment of mixed-race individuals. The demographic difference between British colonies (the United States and Canada) and Spanish and Portuguese colonies (the Caribbean and South America) was exacerbated by the fact that Britain sent complete families to its colonies, whereas Spain and Portugal sent mostly men to its colonies. ${ }^{29}$

As a result,

[i]n the classic Anglo-Saxon patterns of Canada and the United States, there has been a stark dichotomy of black and white, cutting across all political, economic and social lines-and with "black" meaning all individuals of discernible African ancestry, regardless of the degree of racial mixture. In the Latin colonies, however, the small, vastly outnumbered white enclaves followed a divide-and-conquer strategy, making significant legal, economic, and social distinctions between blacks and mulattoes-with the

28. F. James Davis, Who is Black? ONe Nation's Definition 113-14 (1991) (citation omitted). As Davis explained:

$[T]$ o be considered black in the United States not even half of one's ancestry must be African black. But will one-fourth do, or one-eighth, or less? The nation's answer to the question "Who is black?" has long been that a black is any person with any known African black ancestry. ... In the South it became known as the "one drop rule," meaning that a single drop of "black blood" makes a person black... This definition emerged from the Ameriean South to become the nation's definition, generally accepted by whites and blacks alike. Blacks had no other choice.

Id. at 4-5 (citations omitted).

29. SowelL, supra note 8 , at 96. 
latter being elaborately subdivided by skin color or presumed degrees of white ancestry. ${ }^{30}$

Indeed, in certain Latin American societies, the acquisition of wealth had an impact on one's racial categorization so that wealth alone allowed one to become "white." 31 More common, however, was the creation of multiple categories to differentiate between persons of color with differing degrees of white ancestry. Brazil, for example, had a complex system of racial stratification that differentiated among mulattoes or products of mixed-race unions depending upon how many white ancestors the individual had..$^{32}$ Finally, even in certain British colonies in the Caribbean, economic and demographic conditions led to the development of a highly stratified, defined hierarchy based upon skm color. This is in stark contrast with the biracial stratification of races in the United States and Canada that caused all blacks to be classified simply as blacks rather than mulattoes or some other classification. ${ }^{33}$

Obviously, miscegenation is not a phenomenon unique to the United States. What is revealing is how the offspring of miscegenetic unions have been treated by other societies when compared to the treatment of such offspring in the United States. Depending on the society, racially mixed individuals may be treated in one of seven highly distinctive ways. The progeny of racially mixed unions may have (1) a lower status than that of either parent group, (2) a higher status than either parent, (3) an "in-between, marginal" status, (4) a status that varies greatly depending on social class, with color a secondary consideration, (5) the status of an assimilating minority, (6) a status that varies independently of racial traits, or (7) the same status of the lowerstatus group. ${ }^{34}$ I discuss each of these categories in turn.

Under the first category, the issue of a mixed-race union occupy a racial hybrid status lower than either parent. For example, mulattoes in Ghana, Metis ${ }^{35}$ in Canada, Korean Americans in Korea, and Vietnamese Americans in Vietnam occupy a social status subordinate to either parent's status in their respective societies. ${ }^{36}$ This status differs from the "one drop" rule utilized in the United States, which equates the mixedrace offspring with the pure black offspring.

30. Id. at 96-97.

31. Id. at 101.

32. See, e.g., id. at 98-103; see also A.J.R. Russell-Wood, Colonial Brazil, in Nerther Slave NOR FrEE 84, 84-85, 114-15 (David W. Cohen \& Jack P. Greene eds., 1972).

33. SoweLL, supra note 8 , at 105 (discussing the elaborate skin color hierarchy found in West Indian society).

34. DAvis, supra note 28 , at 82 .

35. Metis are defined as the racial hybrids that were the products of interracial unions between French and Scottish trappers and Indian women in Canada. Id. at 83.

36. Id. at $82-83$. 
Conversely, a relatively few societies employ the second category, under which the offspring of an interracial union attain a social status higher than or superior to either parent group. This rare occurrence took place in Haiti, where the inulatto issue of black slaves and whites took control of the country following a successful political revolution. ${ }^{37}$ A similar revolution in Mexico in 1821 produced a ruling class dominated by Mestizos, who are the issue of Spaniards and indigenous Indians. ${ }^{38}$ These Mestizos, as the largest racial group in Mexico, dominate Mexican politics and society as compared to the small numbers of whites and Indians im Mexican society. ${ }^{39}$

Under the third category, employed in South Africa, the issue of mixed-race unions occupy a status that has been characterized as an "in-between" status. This in-between status "is defined as being derived from, but marginal to, both parent groups and intermediate in status. Often there is a firmer tie with one parent group than the other, but sometimes groups in the middle position develop a strong separate identity."40 What is interesting about the racial classification scheme in South Africa, when contrasted with the system in the United States, is that the South African government sometimes ignores the "one drop of blood rule" and reclassifies certain "coloreds," who are clearly mixedrace, as white. ${ }^{41}$

Under the fourth category, as einployed in Latin America, racial identification is highly variable and depends, in part, on class membership. "Racial classification in Brazil is informal and reflects the policy and practice of amalgamation rather than systematic segregation and concern for racial purity. The implied rule is that a person is classified into one of inany possible types on the basis of physical appearance and class standing, not by ancestry. "42 In most of Latin America, Brazil being the notable exception, unmixed Africans are regarded as black regardless of their class standing and cultural attainment. In Brazil, phenotype is largely irrelevant and racial designations change with upward mobility;" hence the phrase "money whitens." 44

37. Id. at 87-88 (discussing the economic and political power of mulattoes, who remained the dominant elites in Haiti for more than a century and a half).

38. Id. at 88-89.

39. Id. at $89-90$.

40. Id. at 90 .

41. Id. at 96-97 (discussing "passing" in South Africa as an open, official, and legalized process of reclassification and discussing the requirements for achieving the status of "pass-white").

42. Id. at 101 .

43. Id. at 101-02 (describing the social groups in Brazil and explaining how education and economics factor into one's identity within Brazilian society).

44. Id. at 101 . 
The fifth category largely describes the status of an assimilating minority. Indeed, the United States utilizes this category to define those immigrant groups who have a racial or ethnic identity other than black. This status is most often associated with the "melting pot" metaphor employed to describe America's official attitude toward inmigrant groups, i.e., that America serves as a vast melting pot for the world's ethnic and racial groups. However, as utilized im America, this status is limited to "one-way" assimilation, rather than true assimilation, as the minority or immigrant group is expected to adopt the norms of the dominant Anglo group.45 Blacks, per the "one drop" rule, are totally excluded from the fifth category despite any attempts to assimilate.

The sixth category, utilized largely in Hawain, employs a highly variable classification scheme that is independent of racial traits. In Hawaii, class status serves as the important variable, and the achievement of one's status in no way turns upon racial or ethnic identification. Although Hawaii is part of the United States and should employ the country's "one drop of blood" rule, the state has rejected this dichotomous classification system as a result of its population mix and its cultural norms. ${ }^{46}$ If racial identification rather than ethnic identification is retained as a viable method of categorizing people in the United States, then the classification scheme in Hawaii would epitomize that goal. However, since race, as currently defined in the United States, is so entrenched and inmutable as a dichotomous classification, I believe the ethnic classification of Hispanics, with the attendant benefits arising from a construction and recognition of ethnicity, is the ideal "racial"-identification heuristic, and should be the goal of this Article. ${ }^{47}$ As I will explain in Part II, this goal can be achieved in other areas of the United States by destabilizing the dichotomous marks of "blackness" and "whiteness" that currently fuel racial identification.

The seventh and last category is the ubiquitous and previously discussed "one drop of blood" rule unique to the United States and its treatinent of blacks. As compared to the other classification schemes detailed above, this dichotonous racial construct is particularly offensive because it elevates whiteness or race over ethnicity as a unifying feature of the dominant group. In this way, the Ainerican scheme manages to constrain all those who are not purely white, either

45. Id. at 117 .

46. Id. at 112-13 (remarking that, despite considerable Americanization in Hawaii, peaceful coexistence of different cultural groups and social participation among groups remain the norm).

47. For a discussion of the benefits attendant to ethnic identification when compared to racial identification, sce infra notes 170-82 and accompanying text. 
visibly, through ancestry, or both, to a subordinate status as a minority even though, in reality, no inajority group exists.

The 1990 Census report supports this proposition. Under current racial classifications, $80.3 \%$ of Americans identify theinselves as "White," $12.1 \%$ as "Black," $2.9 \%$ as "Asian or Pacific Islander," .8\% as "American Indian, Eskimo or Aleut," and 3.9\% as "other."48 Thus, under the current racial classification scheme, whites appear to hold the clear majority. However, when the American population is analyzed under ethnic classifications, no clear majority exists. According to the figures in Thomas Sowell's The Economics and Politics of Race, the population of the United States identified itself as $14 \%$ British (the true Anglo-Saxons), $13 \%$ German, $11 \%$ black, $8 \%$ Irish, and 5\% Hispanic. ${ }^{49}$ These "ethnic breakdowns" demonstrate that no one ethnic group in the United States can claim to be an ethnic majority..$^{50}$

What is startling to note is that if whiteness and blackness are removed as identifiers, and ethnicity is substituted, America looks remarkably diverse and pluralistic, with no one group dominating over any other. Thus, it becoines clear that racial categories are currently used to mask the diversity that characterizes America's ethnic composition. Whites are able to minimize and view as secondary their ethnic differences which, if recognized, would deconstruct and destroy the base dichotomy of "we" or "us" against "them" or "other." White dominance is perpetuated by the presence and opposite definition of blacks. ${ }^{51}$ This biracial classification or taxonomy has the effect of monolithizing blacks and the black experience.

48. Bureau of the Census, U.S. Dep't of Commerce, 1990 Census of Population, General Population Characteristics, United States 3 tbl. 3 (1992).

49. See SowELL, supra note 8, at 183-85. It is important to note that Sowell's information is taken from 1970 Census data. Using 1990 Census data and dividing the total number of people in an ethnic group by the total number of people in the population leads to the following percentage results: 14\% British/Enghish, 16\% Irish, 9.5\% "Afro-American," 7\% Hispanic, 1\% Spanish, 4\% French, and 23\% German. See Bureau of the Census, U.S. Dep't of Commerce, Statistical ABSTRACT OF THE UNITED STATES 19958 tbl. 1, 53 tbl. 56. The percentages are misleading, however, because these more recent Census reports allowed people to report multiple ancestry groups. Id. at $53 \mathrm{tbl}$. 56 . In other words, it would be possible to arrive at a total percentage greater than $100 \%$ of the population using the 1990 data. This current data, because it allowed respondents to identify as belonging to more than one ethnic group, cannot be used to support the claim that no clear majority exists when analyzing the United States population based on ethnic classifications. Consequently, the percentages found in the Sowell book, although dated, allow for a more accurate depiction of this point.

50. See Sowel, supra note 8, at 183. Unlike the other groups listed here, blacks in America are in a unique position. They can be identified racially as blacks. However, they also comprise an ethnic group. I have argued elsewhere that the descendants from African slaves who reside in the United States have shared a "nomos" or a culture of subordination that provides them with a unique history, culture, and identity that qualifies them for ethnic status as African American. See Johnson, supra note 22, at 1414-22. For a further discussion of this ethnicity heuristic, sce infra PART III.

51. Whether American society, absent a significant black population, would be riven by ethnic strife similar to that witnessed in the former Yugoslavia is beyond the scope of this Article. However, 
This is also true for other minority groups currently identified by race. The same biracial taxonomy that creates a black/white racial classification scheme exists to create (rather grossly) a yellow/white classification scheme for Asian-Americans, a brown/white racial classification scheme for Hispanic-Americans, and a red/white classification scheme for Native Americans. In other words, although there is a multiplicity of races or groups that have been identified as racial groups in the United States creating a multi-racial society that belies the notion that there is a "biracial" society, the society is not truly racially pluralistic and diverse because there is a dominant group, whites, against which all the other racial groups are deemed subordinate and inferior.

These other racial groups, of whatever type, share certain uniform traits in this society. Whatever their differences, minorities are regarded as "them" or "other," while whites are viewed as "we" or "u s." Although it is true that the "one drop of blood" rule does not apply with the same degree of exactitude to non-African American members of racial groups, ${ }^{52}$ other minority groups have also been the target of a form of racialism in which the object is the continued preservation of whiteness as a property right in which white is defined as the absence of "other." 33

More importantly, minorities of whatever type suffer from the same biracial taxonomy that creates the black/white racial taxonomy. In other words, in this society the product of a mixed-race union between a

it is interesting to speculate about that issue. I come to the conclusion that no such strife would exist both because of the relative youth of this country, historically, and because, to some degree, all ethnic groups are immigrant groups (with the exception of Native Americans who, sadly, comprise the smallest ethnic group due to this nation's policy of genocide). I do believe, however, that ethnic tensions would be exacerbated.

52.

No other ethnic population in the nation, including those with visibly non-caucasoid features, is defined and counted according to a one drop rule. For example, persons whose ancestry is one-fourth or less American Indian are not generally defined as Indian unless they want to be, and they are considered assimilating Americans who may even be proud of having some Indian ancestry. The same implicit rule appears to apply to Japanese Americans, Filipinos, or other peoples from East Asian nations and also to Mexican Americans who have Central American Indian ancestry, as a large majority do. For instance, a person whose ancestry is one-eighth Chinese is not defined as just Chinese, or East Asian, or a member of the mongoloid race.

DAvis, supra note 28, at 12 .

53. Michael Omi \& Howard Winant, Racial Formation in the United States from THE 1960s TO THE 1980s 75-76 (1986) (discussing the "politics of race" throughout U.S. history and, specifically, in California). The authors note that while Mexicans were defined as a "white" population in the wake of the 1848 Treaty of Guadalupe Hidalgo, the California Supreme Court, in People v. Hall, 4 Cal. 399 (1854), classified the Chinese as "Indians" and denied them the political rights afforded to whites. OMI \& WINANT, supra. The ideological residue of these restrictions in naturalization and citizenship is the current popular equation of the term "white" with "American," while blacks, Mexicans, Orientals, etc., are seen as "other Americans." 
member of a minority race and a white person is treated, if the visible morphology identifies that person as a product of a mixed-race union, as a full-fledged member of the minority group and not any differently than a member of the minority group whose parents are both "pure" members of the minority group.

Consequently, to the same extent and, as noted below, for the same reasons that no mulatto category has developed in American society to racially categorize the offspring of a white and a black, no mixed-race or other category has developed to place the products of mixed-race unions when the minority-group ancestor is a member of a non-black minority group. If the issue of a white man and an Asian woman were treated as white or, more realistically, recognized separately and equally as an "other" or mixed-race, ${ }^{54}$ that would have the effect of weakening the power and property right in whiteness and inevitably lead to a weakening of the white/black dichotomy. The destruction of these base elements of biracial classifications would seriously weaken if not destroy racism. In their place, ethnic identity would become important for a sense of self. ${ }^{55}$

\section{B. Color Consciousness-Entrenchment of the Racial Dichotomy in the Black Community}

The existence of a racial dichotomy in American society has been detrimental and destructive to blacks. As I will explain in this section, the concept of "Color Consciousness" embraced by many within the black community has the effect of perpetuating this destructive dichotomy. The term Color Consciousness, as I have defined it, refers to the black community's pervasive tendency to accord special treatment or worth to those members who, although black, possess certain features (straight hair, thin lips, and a narrow nose, for example) that identify those individuals as the product of a mixed-race union, either directly or somewhere previously in one's genealogical tree. ${ }^{56}$ In this sense, the black community embraces and condones the white/black dichotomy-adopting white as the all-important metric by which one is measured. However, as explained above, white society refuses to afford preferential status to mixed-raced individuals with some degree of white ancestry. Thus, the theory of Color Consciousness has the effect of

54. For a discussion of cultures in which such an offspring would attain equal or superior status to that of the parents based on racial identification, see supra notes 37-39 and accompanying text.

55. For an extensive discussiou of the destabilization of race as an identifier and the substitution of ethnicity as the dominant classification scheme, see infra Parts II and III.

56. The noted writer, Alice Walker, has characterized this pheuomenon as "colorism," defined as the "prejudicial treatment of same-race people based ou skin color [that] contiuues to this day." Itabari Njeri, Sushi and Grits: Ethnic Identity and Conflict in a Newly Multicultural America, in LURE AND LOATHING, supra note 6, at 13, 16 (summarizing Ahice Walker's theory of colorism). 
perpetuating the racial dichotomy with no corresponding benefit to this mixed-race population. ${ }^{57}$

To understand why blacks embraced the theory of Color Consciousness, one must first examine the lack of black culture or ethnicity in American society as perceived by whites. Under the current racial dichotomy, whites are allowed to have both race and ethnicity, while blacks are only allowed race. ${ }^{58}$ The existence of slavery in early American society made such an anomaly possible. Under slavery, whites were able to effectively obliterate the slave's individual identity as an equal or person by erasing all ties to the slave's country of origin. ${ }^{59}$ This obliteration of the slave's geographic or tribal identity was further hastened by the level of forced miscegenation that occurred. ${ }^{60}$ Because blacks were denied an ethnic identity, race and racial identification quickly became the exclusive means of identification.

When slavery was abolished, and blacks were finally allowed to freely deploy their culture and embrace their ethnicity, they had been enslaved and separated from their native culture and ethnicity for centuries. Retrieving that culture and ethnicity was like trying to capture bubbles floating in the wind. Blacks were thus left with a choice to either embrace and work within the racial classifications that had long defined their existence, or to attempt to reconstruct an ethnic heritage almost entirely obliterated by slavery.

Blacks who employ or embrace Color Consciousness have reified artificial racial boundaries by accepting a definition of white as good and meritorious and by measuring one's sense of what is good and meritorious (at least racially) against that standard. In other words, blacks, lacking a viable separate culture and ethnic identity, attempted to fill the cultural void created by the lack of ethnicity by embracing what

57. As Alice Walker once wrote, unless we exorcise colorism, "we cannot as a people progress. For colorism, like colonialism, sexism and racism, impedes us." Id. at 16 (quoting Alice Walker).

58. See OMI \& WINANT, supra note 53, at 23 (discussing theorists' lack of attention to ethnic distinctions, such as national origin, religion, and culture, among blacks). I find it instructive that ethnic categories, such as Italian, Polish, and German, all define individuals who are racially identified as white. By contrast, blacks are not commonly associated with ethnic categories. Instead, they are simply Iumped together as blacks.

59. This statement presupposes that ethnicity is correlated with a country of national origin. For support of this proposition, see id. at 15 (defining and describing ethnicity based on national origin in such a way that race becomes a "social" category).

60. Some, like Professor Thomas Sowell, have unearthed statistical evidence that a significant percentage of the intermixing may have been voluntary encounters resulting from exogenous demographic factors such as a preponderance of white males and black females in southern urban areas and a corresponding paucity of white females and black males. THOMAS SowELL, RACE AND CULTURE: A WORLD VIEW 207 (1994). Of course, even if that sort of miscegenation may be construed as "voluntary," the facts which led to the disparity in numbers were not; those facts were created expressly by the institution of slavery. See infra text accompanying note 187. 
ultimately turned out to be the destructive norms of integration. Those who employ and embrace Color Consciousness have employed a standard that white society refuses to recognize-gradations of race. This has the effect of reinforcing the dichotomy between white and black because in the black community one is measured, to a degree, by how white one is, not by other factors. White then becomes the allimportant metric by which one is measured.

Blacks adopted the assimilationist norms of immigrant groups by embracing integration as a strategy to overcome racism. By that I mean, blacks have not only embraced integration as an ideal, they have embraced it as a process of matriculation into American society to the detriment of establishing a base community or nomos ${ }^{61}$ from which meaningful integration (that is, from strength and appropriate values) could precede.

As a result of behavior predicated on integrationism as both a norm and a process through which to achieve success in American society, such as black flight from the inner cities to the suburbs, ${ }^{62}$ Color Consciousness and the internalization of norms associated with it, and the resultant lack of interdependent black communities, ${ }^{63}$ individual black success is plausible and possible, but group success and enrichment are precluded. ${ }^{64}$

Thus, although whiteness is a goal that can never truly be achieved by blacks since blackness is characterized biologically as a dominant genetic trait, by employing Color Consciousness, blacks internalize the dichotomous racial classification within their own subordinate status (from the perspective of whites who view them as "other"). This has the effect of reinforcing the distinction between the two groups. Instead of recognizing how similar a visibly "white-featured" mulatto is to a white person, the visibly white black (per the "one drop of blood" rule) is regarded as a black by whites and as a "preferred" black by those blacks who practice Color Consciousness. That preference accorded the lighter-hued or light-skinned black by other blacks sends the signal that it is whiteness that is prized and exalted above all other traits and characteristics. That has the effect of keeping in place the artificial

61. For a definition of "nomos," see supra note 22.

62. See Alex M. Johnson, Jr., How Race and Poverty Intersect to Prevent Integration: Destabilizing Race as a Vehicle to Integrate Neighborhoods, 143 U. PA. L. Rev. 1595, 1598 n.10, $1608,1609-16$ (1995) (explaining that, although blacks attempt to flee from the ghettos to the suburbs, they are largely unsuccessful due to the effects of racism and poverty).

63. 1 owe the term and the insight to my former student, Eric Broyles.

64. However, even individual success is minimized or marginalized by the majoritarian community, as the successful black is not thought of as authentically or truly black. For a discussion of the inauthentically black, see Johnson, supra note 62, at 1628-29; for a discussion of how whites marginalize or "fenee off" successful blacks, see infra text accompanying notes 136-38. 
dichotomy that has developed by according some benefit-some worth and value - to the characteristic of whiteness.

Color Consciousness is, consequently, counterproductive for blacks and should be recognized as a logical consequence of racism in American society. In essence, by adopting Color Consciousness, the black community chose the wrong strategy in their dilemma to overcome the racism engendered by slavery and other societal factors. A better, more appropriate, strategy for the group would have been to emphasize and internalize the norms of their separate community. This would have had the effect of maintaining ethnic identity within their communities. What this means for the future is noted and discussed below, but suffice it to say that ethnicity, its creation and its maintenance, appears to be the key. ${ }^{65}$

\section{II \\ LEARNING FROM TRADEMARK LAW}

\section{A. Defining the Mark}

The law of trademarks would seem to have little to do with issues of race and racial identification. However, the principles of trademark law provide surprising insight into the formation of dichotoinous racial classifications in the United States. As Judge Richard Posner has written, "The economic function of trademarks is, by giving assurance of uniform quality, to economize on consumer search costs." ${ }^{\text {"66 }}$ Racial identification operates, to a large degree, in a remarkably similar fashion. The racial identification of the individual, which is one of the first attributes noticed by an observer, ${ }^{67}$ provides information to the user/consumer that economizes on that consumer's search costs in making judgments about the individual who is previously unknown.

Before explaining in detail the link between racial classifications and trademark law, a brief overview of the economic theory of property and trademark law is necessary. One of the main purposes of trademarks is the promotion of economic efficiency. ${ }^{68}$ As Landes and Posner explained:

The economics of property rights, on which our analysis of trademark draws heavily, are well understood and can be suinmarized quite briefly. A property right is a legally enforceable power to exclude others from using a resource, without need to

65. For an extensive discussion of the destabilization of race as an identifier and the substitution of ethnicity as the dominant classification scheme, see infra Parts II and III.

66. Richard A. Posner, Economic ANalysis of Law 43 (4th. ed. 1992).

67. See infra note 98.

68. See William M. Landes \& Richard A. Posner, Trademark Law: An Economic Perspective, 30 J.L. \& ECON. 265, 265-66 (1987). 
contract with them. So if A owns a pasture, he can forbid others to graze their cattle on it without having to negotiate an agreement for exclusive use. A property right confers two types of economic benefits, static and dynamic. The former is illustrated by a natural (that is, uncultivated) pasture. If the owner cannot exclude others from using his pasture, there will be overgrazing because users of the pasture will ignore the costs they impose on each other .... The dynamic benefit of a property right is the incentive that the right imparts to invest in the creation or improvement of a resource in period 1 (for example, planting a crop), given that no one else can appropriate the resource in period 2 (harvest time). For example, a firm is less likely to expend resources on developing a new product if competing firms that have not borne the expense of development can duplicate the product and produce it at the same margmal cost as the innovator; competition will drive price down to marginal cost, and the sunk costs of invention will not be recouped. ${ }^{69}$

A trademark attempts to economize property rights by allowing an individual or firm to use a word (for example, "Coca Cola") ${ }^{70}$, symbol (e.g., five differently colored interlocking rings for the Olympics) ${ }^{71}$, or other signifier (for example, the color pink, which is registered as a trademark for residential insulation manufactured by Owens-Corning) ${ }^{72}$ to designate a product, good, or service. Efficiency is achieved in two respects. First, consumer search costs are reduced because the consumer is able to quickly and easily identify or locate the product that is desirable. Second and relatedly, transaction costs are reduced to a degree (what Landes and Posner call "the distinct (and unconventional) market in language") ${ }^{73}$ because the buyers and sellers are able to accurately and effectively communicate about the products, goods, and services traded.

In a similar fashion, an observer utilizes racial classifications to minimize search/transaction costs by attributing to an individual certain

69. Id. at 266 (citations omitted). This last sentence describes the process of destabilization as I envision it. This article views the races as competing firms with whites producing the superior product and blacks the inferior product thus far due to factors beyond their control. The goal of destabilization would be to allow blacks either to duplicate the product produced by whites, thereby weakening and nullifying its value, or to produce a new product that is of equal value to the white product. For a complete discussion on destabilization, see infra notes 142-163 and accompanying text.

70. See, e.g., Coca-Cola Co. v. Overland, Inc., 692 F.2d I250 (9th Cir. 1982) (holding that "Coca-Cola" and "Coke" were not generic terms and that restaurant operator was required to inform customer before substituting a beverage produced by another manufacturer).

71. See 36 U.S.C. $\$ 380(a)(1)$ (1994) (prohibiting the unauthorized use of the symbol of the International Olympic Committee, "consisting of 5 interlocking rings").

72. For a discussion of the development of color as a trademark and the case approving the Owens-Coming tradeinark, see infra notes 142-146 and accompanying text.

73. Landes \& Posner, supra note 68 , at 269. 
characteristics associated with the racial group to which that individual belongs. Although I have made no exhaustive attempt to compile the racial traits that comprise the trademark of "black" or "blackness," a few characteristics readily come to mind to define what I mean when I characterize the racial categorization of a person of color as black. ${ }^{74}$ First and foremost is the notion that blacks are imtellectually inferior to whites due to some innate trait that is tied to their race ("intellectual inferiority attribute"). ${ }^{75}$ Somewhat related and almost compensatory is the notion that what is lacking in intellectual endowments is more than made up in the athletic endowments of blacks ("athletic superiority attribute"). ${ }^{76}$ The common misconception is that blacks are physically gifted in ways that make them better athletes, dancers, and performers than whites. ${ }^{77}$

Connected or associated with the athletic superiority attribute is the attribution to blacks of sexual promiscuity ${ }^{78}$ and/or physical endowment of superior male sexual organs ("sexual superiority attribute"). In addition, indolence or laziness historically has been associated with black racial identification ("indolent inferiority attribute"). ${ }^{79}$ The indolent inferiority attribute appears to be a product of the intellectual inferiority attribute and the athletic superiority attribute in that blacks are viewed as too dumb to be industrious, and, like physically superior

74. The word "black" has so many negative connotations that to identify somcone as a "black" person while not ascribing to that person negative attributes is a major feat. While writing this article I used the WordPerfect thesaurus function to produce the synonyms for "black." Eliminating the synonyms that are related to color, the rest of the synonyms are: murky, shadowy, tcncbrous, forbidding, menacing, ominous, threatening, evil, iniquitous, nefarious, wicked, dismal, gloom, and melancholy. On the other hand, the antonyms, other than white, are light, inviting, moral, and cheerful. A partial list of the synonyms for white includes pure, spotless, undefiled, and unsullied.

75. See, e.g., William Shoekley, Dysgenics, Geneticity, Raceology: A Challenge to the Intellectual Responsibility of Educators, 53 PHI DeLTA KAPPAN 297, 303-04 (1972); Jeremy Gerard, CBS Gives Rooney a 3-Month Suspension for Remarks, N.Y. TIMEs, Feb. 9, 1990, at C30 (reporting on political commentator Andy Rooney's statement that blacks are less intelligent because they have "watered down their genes"). For an interesting discussion of anthropological and psychological theories of the innate intellectual inferiority of blacks, see STEPHEN L. CARTER, REFLECTIONS OF AN AfFiRMative ACtion BABY 181-86 (1991).

76. One recent and well publicized example of individuals attributing to blacks athleticism or other qualities as a result of their race and concomitant genetic attributes is Jimmy "The Greek" Snyder's assertion that slave breeding contributed to black's big thighs and butts, allowing them to become exceptional football players and athletes. See Dave Anderson, 'Greek' Loses an Out Bet, N.Y. Times, Jan. 17, 1988, $§ 5$, at $1,4$.

77. See Johnson, supra note 5 (arguing that a disproportionate number of blacks are represented in these ficlds, not because of their athletic superiority, but rather because of pervasive racism in vocations other than sports and entertainment).

78. RICHARD A. POSNER, SEX AND REASON 140 (1992) (discussing differences between blacks and whites with regard to sexual behavior).

79. See, e.g., JAN N. Pieterse, White on Black: IMAges of Africa and Blacks in Western Popular Culture 90-91 (1992). 
animals, are assumed to be listless or in repose when not engaged in enjoyable physical activity like sports or sex..$^{80}$

The last attribute that I assign to the trademark of black or blackness is perhaps the most recent to develop and the most complicated to explain. A confluence of factors has created the view that blacks are more violent ${ }^{81}$ than whites and engage in a disproportionate amount of criminal behavior ("violence superiority attribute"). ${ }^{82}$ Whether that is true or not, it is important to note that this same criminal behavior is portrayed as a threat to whites in their community, even though most crime is local and most victims of black criminals are black people. ${ }^{83}$ Emblematic of this attribute is the use of Willie Horton by then-Vice President Bush as a campaign symbol in the 1988 Presidential election to scare white voters into voting for him to protect themselves from black crime. ${ }^{84}$

When all of these attributes are considered together, being black in American society today is a tough responsibility which carries considerable negative baggage that is hard to overcome. ${ }^{85}$ An individual who is identified as a black person, either visually ${ }^{86}$ or through other

80. As for the historical antecedent that Africans are animals, see id. at 39-44.

81. See Smith, supra note 18 , at 4 (reporting that blacks are perceived to be more violent than whites).

82. See, e.g., Bureau of Justice Statistics, U.S. Dep't of Justice, Report to the Nation on CRIME AND Justice 47 (2d ed. 1988) [hereinafter Report to the Nation on Crime AND JUSTICE] (citing statistics indicating that the number of black criminals in the United States is disproportionately high). For a discussion of black criminality, see generally Regina Austin, "The Black Community," Its Lawbreakers, and a Politics of Identification, 65 S. CAL. L. REv. 1769 (1992).

83. See REPORT TO THE NATION ON CRIME AND JUSTICE, supra note 82, at 33 (reporting that $83 \%$ of white victims are attacked by white perpetrators and that $89 \%$ of black victims are attacked by black perpetrators); Federal Bureau of INVEstigation, U.S. DEP'T OF Justice, CRIME IN THE UNITED STATES 17 tbl. 2.8 (1994) (reporting that in a total of 11,173 homicides, 5,527 of the victims were black and 5,106 of the perpetrators were black). Some estimate the percentages of black-on-black crime to be as high as 90\%. The Racial Injustice Act, DETrort NEws, Apr. 15, 1994, at $10 \mathrm{~A}$ (reporting that $90 \%$ of crimes against blacks are perpetrated by blacks).

84. See, e.g., Richard Lacayo, Back to the Party of Lincoln?, Time, Jan. 2, 1989, at 79 ("The most prominent black in the George Bush campaign was Willie Horton...."); see also CARTER, supra note 75 , at 156 :

In the fall of 1988, it will be recalled, the nation's television screens were saturated with images of Horton, the black killer and rapist who committed despicable crimes after escaping from a Massachusetts work-release furlough program-the point, it seems, being to suggest that if Miclrael Dukakis were elected president, there unight be a lot more Willie Hortons roaming the streets.

85. If you string these attributes together, it is remarkable to see how they are all related in the sense that they are somewhat anthropomorphic. Viewing blacks as dumb, physical, sexually active, indolent, and violent individuals is attributing to them claracteristics of a dangerous animal. Perhaps this should not be surprising since the origins of slavery and racism can be traced to a notion that blacks are subhuman and more related to animals than to white people. See, e.g., Pieterse, supra note 79, at 39, 41-43.

86. See id. at 39-44. For example, under the "rule of recognition" defined by Professor Gotanda, "[a]ny person wliose Black-African ancestry is visible is Black." Gotanda, supra note 6, at 24. 
means ${ }^{87}$, faces the prospect that a significant percentage of the majoritarian population, as well as some of the minority community, ${ }^{88}$ assign to that individual some or all of the attributes discussed above solely due to that individual's categorization as a black person. To paraphrase Landes and Posner, individuals who perceive differences between races, however those differences have historically developed, ${ }^{89}$ view race as follows: racial identification acts as a trademark conveying information that allows the consumer to say to himself, "I need not investigate the attributes of the [person] I am about to [meet (relate with)] because the [skin color or race] is a shorthand way of telling me that the attributes are the same as [those of all the (insert race) I have met and know of]." Consequently, race and racial identification act as a form of trademark, allowing consumers in this market to make decisions and engage in behavior based on information they glean solely from the racial identification (the brand) of the individual or group being characterized.

However, the trademark of black or blackness, which categorically attributes each of the features discussed above to all members of the black population, is based upon a logical fallacy. This is evidenced by the fact that there is no scientific correlation between the trademark of blackness as described above and the characteristics actually possessed

87. Pursuant to the "[r]ule of descent: (a) Any person with a known trace of African ancestry is Black, notwithstanding that person's visual appearance; or, stated differently, (b) the offspring of a Black and a white is Black." Gotanda, supra note 6, at 24.

88. See, e.g., Austin, supra note 82 , at 1770 (noting that black appraisals of black criminal behavior are often in accord with those of the dominant society).

89. This Article does not attempt to develop a theory of why or how our current racial differences developed. Suffice it to say, those differences based on race are largely historically produced and societally contingent. Why we continue to exploit those differences despite the fact that the historical justification - slavery - is no longer viable and that racialism and racism generally are recognized as morally wrong is also beyond the scope of this Article. In a recent article, Richard McAdams attempts to explain this continued exploitation by arguing that, in order to succeed, groups create "intra-group status rewards" to induce individual members to contribute to the group's welfare. Furthermore, McAdams demonstrates that the same status motivation causes group members to seek to raise the relative status of their own group by lowering the status of other groups and that this status production model explains, to a significant degree, the existence of racial discrimination from an economic perspective. See Richard H. McAdams, Cooperation and Conflict: The Economics of Group Status Production and Race Discrimination, 108 HARv. L. Rev. 1003, 1007, 1023-33 (1995).

90. Landes \& Posner, supra note 68 , at 269 . This model of behavior is patterned on the model of statistical discrimination that is used in employment contexts to discriminate against minorities:

[Statistical discrimination] occurs beeause information about an employee's qualifications is often costly to obtain. An employee's race, however, is cheaply ascertained. Therefore, if a firm concludes that an employee's race correlates with his or her qualifications, and if better information about the qualifications is too costly to discover, it will be rational, profit-maximizing behavior for the firm to offer lower wages to a minority employee than it would offer to a nonminority employee.

David A. Strauss, The Law and Economics of Racial Discrimination in Enployment: The Case for Numerical Standards, 79 GEo. L.J. 1619, 1622 (1991) (citations omitted). 
by black individuals. As biologists have noted, apart from the visible morphological characteristics of skin, hair, and bone, which form the basis for racial classifications, genetic variability among races is not much greater than that within races. ${ }^{91}$ In this sense, the trademark of black or blackness is inefficient because it communicates erroneous information to the observer, causing her to conclude that the individual being observed possesses attributes that do not necessarily correspond with that individual's actual disposition.

Race contimues to exist as a classification mechanism because of the highly visible and easily identifiable features of color, hair, and bonewhat Professor Appiah characterizes as the "grosser" morphology of an individual. ${ }^{92}$ Elsewhere, this classification scheme has been characterized as "racialism," which posits "that there are heritable characteristics," including, but not limited to, skin color, bone structure, and hair, "possessed by members of our species, which allow us to divide them into a small set of races, in such a way that all the members of these races share certain traits and tendencies with each other that they do not share with members of any other race."93

Although I am convinced by the claims of geneticists and biologists that there are no "real" genetic differences between whites and blacks, ${ }^{94} \mathrm{I}$ am unwilling to concede, as Professor Appiah does, that

91. A quote from Professor Appiah's work both summarizes and buttresses this observation: The evidence in the contemporary biological literature is, at first glance, misleading. For despite a widespread scientific consensus on the underlyiug genetics, contemporary biologists are not agreed on the question whether there are any human races. Yet, for our purposes, we can reasonably regard this issue as terminological. What most people in most cultures ordinarily believe about the significance of "racial" differences is quite remote from what the biologists are agreed on. ... Every reputable biologist will agree that human genetic variability between the populations of Africa or Europe or Asia is not much greater than that within those populations, though how much greater depends, in part, on the measure of genetic variability the biologist chooses.... Apart from the visible morphological characteristics of skin, hair, and bone, by which we are inclined to assign people to the broadest racial categories-black, white, yellow-there are few genetic characteristics to be found in the population of England that are not found in similar proportions in Zaire or in China, and few too (though more) that are found in Zaire but not in similar proportions in China or in England. All this, I repeat, is part of the consensus.

APPIAH, supra note 2, at 35 (citations omitted).

92. Id. at 36 .

93. Id. at 13 .

94. Id. at 36-37 (citing Masatoshi Nei and Arun K. Roychoudhury, Genetic Relationship and Evolution of Human Races, 14 EvolutionaRY BIOLOGY 1, 44 (1983)) (discussing race and morphology).

Furthermore, as Thomas Sowell notes:

The term "race" was once widely used to distinguish the Irish from the English, or the Germans from the Slavs, as well as to distinguish groups more sharply differing in skin color, hair texture, and the like. In the post-World War II era, the concept of "race" has more often been applied to these latter, more visibly different, categories, and "ethnicity" to different groups within the broader Caucasian, Negroid, or Mongoloid greupings. However, this dichotomy between race and ethnicity is mislcading in its apparent precision. Neither race nor related concepts can be used in any scientifically precise sense to refer to the people inhabiting this planet today, after centuries of genetic intermixtures. The more 
we should abandon the term "race" and substitute in its place the term "culture." The fact that there is no scientific basis for race does not mean that race and racial classification and the racism that flows from them does not exist. Those very things that Professor Appiah minimizes-the "grosser" features or morphology of hair, skin, and bone-serve as the basis for the determination of race, as well as other characteristics, such as intelligence, even if the latter features cannot scientifically be correlated with genetic markers, DNA, or other scientific measurements. The fact that the "grosser" morphology of hair, skin, and bone is important is irrecusable. Although there may be no scientifically fixed basis or definition of race, the social construction of race based on those grosser features is incontrovertible. ${ }^{96}$

I agree with Thomas Sowell, who recently noted: "Whatever the biological reality, race as a social concept is a powerful force uniting and dividing people. Whether visible on the physical surface or simply felt in the emotional depths, race provides the cohesive groupings in which cultures have been concentrated, transmitted, and carried around the world." 97

generic term, race, will be used here in a loose sense to refer to a social phenomenon with a biological component, rather than make a dichotomy whose precision is illusory.

Sowell, supra note 60, at 6; see also Christopher A. Ford, Administering Identity: The Determination of "Race" in Race-Conscious Law, 82 CALIF. L. REv. 1231, 1239 (1994) (arguing that a person's raeial identity is largely a social rather than a biological phenomenon).

More recently, a popular press article summarized the scientific debate about genetic racial identification as follows:

About 70 percent of cultural anthropologists, and half of physical anthropologists, reject race as a biological category.... Empirical evidence, woven into a theoretical whole, is what matters. The threads of the argument against the standard racial categories:

GENES: In 1972, population biologist Richard Lewontin of Haryard University laid out the genetic case against race. Analyzing 17 genetic markers in 168 populations such as Austrians, Thais and Apaches, he found that there is more genetic difference within one race than there is between that race and another. Only 6.3 percent of the genetic differences could be explained by the individuals' belonging to different races. That is, if you pick at random any two "blacks" walking along the street, and analyze their 23 pairs of chromosomes, you will probably find that their genes have less in common than do the genes of one of them with that of a random "white" person. Last year the Human Genome Diversity Project used 1990s genetics to extend Lewontin's analysis. Its conclusion: genetic variation from one individual to another of the same "race" swamps the average differences between raeial groupings. The more we learn about humankind's genetic differences, says geneticist Luca Cavalli-Sforza of Stanford University, who chairs the committee that directs the biodiversity project, the more we see that they have almost nothing to do with what we call race.

Sharon Begley, Three is Not Enough: Surprising New Lessons from the Controversial Science of Race, NEWSWEEK, Feb. 13, 1995, at 67, 67.

95. See Jayne C. Lee, Navigating the Topology of Race, 46 Stan. L. Rev. 747, 754 (1994) (reviewing ApPIAH, supra note 2) (summarizing Appiah's theory on race and culture).

96. 'From numerous cross-cultural studies, it is clear that the social determination of which differences matter and the attribution of meaning to these differences, not the existence of physical differences, influence a society's racial categories." Id. at 761 n.66.

97. Sowell, supra note 60 , at 6 . 
However, in light of the scientific evidence summarized above, it is difficult to understand why American society continues to embrace the inefficient trademark of black or blackness, whicl elevates the "grosser" difference in morphology over other physical differences such as eye color, height, or weight. ${ }^{98}$ I contend that the negative trademark of black or blackness continues to exist largely to preserve the economic status of the white community.

At base, it must be recognized that as racial categories have developed and evolved in this society, they have acquired the attributes of a property right. In particular, whiteness has evolved into a form of racialized property that whites seek to protect and exploit. ${ }^{99}$ Returning to our economic definition of property, ${ }^{100}$ whiteness has all the traditional attributes of property in that it is transferable from one generation to the next, ${ }^{101}$ and, although hard to quantify precisely, ${ }^{102}$ it is a "thing to which a man may attach a value and have a right."103

98. Indeed, psychological literature reveals that people categorize other people based on three visual referents: gender, age, and race. Physical appearance, e.g., eye color, height, and weight, has less infiuence on the individual who seeks to portray individuals by categorizing them.

What then are the core categories that people use to portray other people? Some characteristics are visually and immediately accessible: the top three are gender, age, and race. Mounting evidence suggests, however, that subtypes constitute the basic-level categories that perceivers habitually use. People have in mind specific types of the elderly, women, and blacks. People also use subtypes that combine gender and race, age and race, as well as ethnicity and domain....

If age, race, and gender are important by virtue of being visually conspicuous, then appearance in general should be an important basis for stereotypes. A meta-analytic view of the physical attractiveness stereotype indicates that it is moderately strong for perceived social competence; weaker for perceived potency, adjustment, and intellect; and negligible for integrity and interpersonal concem.

Susan Fiske, Social Cognition and Social Perception, 44 ANN. Rev. Psychol. 155, 166 (1993) (citations omitted).

These physical differences do matter, but to a lesser extent than racial classifications. For example, eye color can be correlated with race to some degree (blue eyes are associated with "Nordic" features that are prized by whites). In addition, studies indicate that overweight people sometimes experience job discrimination. See, e.g., Fat People's Fight Against Job Bias, U.S. News \& WORLD REP., Dec. 5, 1977, at 78.

99. See, e.g., Harris, supra note 6, passim.

100. See supra notes $68-73$ and accompanying text.

101. The fact that racial status has been deflned by both the "rule of descent" and the "one drop of blood" rule supports the view that white racial identity has inherent value capable of being transferred to one's issue. See Gotanda, supra note 6, at 23-27. To a limited extent, racial identity resembles the investment in human capital that one makes in choosing to obtain or pursue an advanced educational degree in that the direct property or benefit itself, the degree, may not be transferred to the issue, but the indirect benefits of having that degree will more than likely benefit the issue of that individual. The fact that whiteness qua whiteness cannot be alienated inter vivos as a market good is not destructive of its characterization as a property right. See Margaret J. Radin, Market-Inalienability, 100 HARV. L. REv. 1849, 1852-53 (1987).

102. See Harris, supra note 6, at 1759 (quoting ANDREW HACKER, Two NATIONS 32 (1992)).

103. Id. at 1726 (quoting 6 JAMEs MAdison, ThE Writings of JAMEs MAdison 101 (Gaillard Hunt ed., 1906) (quoting James Madison, Property, NAT'L GAzETTE, Mar. 29, 1792, at 174)). 
Lastly, it is a property right in that those holding that right may and do attempt to exclude others from using that right. ${ }^{104}$

Whiteness as a property right confers both types of economic benefits-static and dynamic-on its recipients. The static benefit conferred upon whites by the maintenance of the property rights of whiteness is twofold. First, whites attain a type of racialized privilege that is dependent on the existence of whiteness as a property right consisting of the absence of black or blackness. ${ }^{105}$ Second, and this is simply the reverse of the racialized privilege argument, whites exist in a world in which they not only define what is dominant and extract privileges based on that dominance, but are viewed as "we" or "u s" and those that are excluded are viewed as "other." 106 This leads logically to the dynamic benefit they derive from the property right of whiteness-status rights.

In his article, Richard McAdams demonstrates how whites overcome collective-action problems both by creating intra-group esteem and by engaging in inter-group conflict in an attempt to lower the status of outside groups relative to their own. ${ }^{107}$ The determination, then, that one has a superior group is based upon a determination that other groups are inferior. The fact that the status of the white group is interdependent upon the status of the outside group indicates that black and blackness are just as much a property right as white and whiteness. Without other racial groups, there would be no inter-group competition that would produce status. Similarly, the equivalent of a competing product in the marketplace of self-identification and worth is necessary in order to measure one's own product as superior or inferior. In the struggle for recognition, black and blackness become the inferior product in the marketplace, and the mark of black and blackness become associated with inferior attributes. ${ }^{108}$

Consequently, what we think of as "racial stereotyping" represents the product of the trademark phenomenon as opposed to the creation. Let us assume that it is verifiable that blacks, for whatever reason, are better athletes, ${ }^{109}$ are more aggressive (which leads to being more

104. Indeed, the "one drop of blood" rule and the rule of descent properly should be viewed as mechanisms for maintaining the exclusivity of the right and forbidding those who do not qualify from using the right and the privileges associated with it.

105. Harris, supra note 6 , at 1741-45.

106. For a discussion of "other" and "otherness," see PIETERSE, supra note 79, at 224-34.

107. McAdams, supra note 89, at 1023-33, 1056-62 (explaining that individuals are willing to sacrifice for the group in order to ultinately achieve or maintain higher status for themselves within the white group; the white group, in tum, gains status for all of its meinbers by engaging in competitions with other groups).

108. See supra notes 75-84 and accompanying text.

109. See Johnson, supra note 5. 
violent) ${ }^{110}$ have less intelligence (as measured by standard aptitude or IQ tests), ${ }^{11}$ are more sexually active (when measured by such indices as average number of partners by the age of 21 or illegitimate births), ${ }^{112}$ and by all indices are poorer and live in less habitable dwellings and neighborhoods. ${ }^{113}$

Many of these categories are admittedly negative when viewed from the perspective of societal norms and objectives, ${ }^{114}$ and the existence of these categories has led some to contend that in certain situations, discrimination is rational because race serves as a rational proxy for discrimination. As Cass Sunstein has noted:

There can be no question that at least in some contexts, race and sex operate as similar proxies. In various ways, blacks differ from whites and women differ from men; there are "real differences" between the two groups. Indeed, in light of past and present discrimination against blacks and women, it wonld be shocking if group-based differences were not present. Women, for example, are more likely than men to be the primary caretakers of children and more likely to leave the employment market because of that role. Along every indicator of social welfare-poverty, education, employment, vulnerability to private (or public) violence, participation in violent crime-blacks are less well-off than whites.... Indeed, it is fully possible that race or sex is, in some contexts, every bit as accurate a signaling device as, say, test score, education, and previous employment. ${ }^{115}$

What is puzzling, however, are both the predictive and normative bases that lead to the conclusions supporting the stereotype. If, turning to the predictive first, we assume that there is no scientific basis for racial definition, how is it that one can identify one group, that is, blacks, exhibiting uniform or nearly uniform traits that cause the various

110. See Massey, supra note 4, at 1206.

111. See HeRrnstein \& MURRAY, supra note 3, at 269.

112. POSNER, supra note 78 , at 140.

113. See Johnson, supra note 62 , at 1606-08.

114. The exception may be athleticism, but, even there, the flip side of athleticism appears to be a belief in the lack of intelligence so that one is viewed as a tradeoff for the other.

As Pieterse notes,

The achievements of black athletes who have challenged 'white supremacy' and of blacks in the Olympics are all breaches of the myth of racial inferiority. The integration of sport is part of overall black integration. But it is also a limited kind of success. For blacks there is a place in the circus, as gladiators. Their success seems to confirm one of the stereotypes of the black as bestial brute, the 'all brawn and no brains' kind of athlete. Besides, new racial myths have been created to 'explain' the sports achievements of blacks. At first the story was that blacks were inferior to whites in every respect, physically as well, and therefore unfit to compete with whites. That some turned out to have greater physical prowess than whites, led to other stories.

PieTERSE, supra note 79, at 149.

115. Cass Sunstein, Why Markets Don't Stop Discrimination, Soc. PHIL. \& PoL'Y, Spring 1991, at 22, 27 (citation omitted). 
negative stereotypes? Are blacks voluntarily engaging in stereotypical behavior in greater proportion to non-blacks, or is stereotypical behavior imposed upon all those who are identified as black, regardless of their individual preferences? This question cannot be answered correctly if the defining feature of blacks or blackness is derived solely through the mark, which has likely become a self-fulfilling prophecy for most blacks.

Turning to a normative inquiry, which, for the sake of discussion, accepts both a stable and fixed definition of black as given and stereotypical behavior on the part of the group as a statistical reality, one must question why such stereotypical behavior leads to rational or other sorts of discrimination. Why are these attributes-less intelligence, more athleticism, sexuality, and even aggressiveness which leads to violenceviewed negatively? ${ }^{116}$ Is it because they are possessed to a greater degree by blacks, who are viewed as inferior and subordmate to whites, and therefore can only disproportionately possess inferior attributes? Or are blacks perceived to have these attributes to a greater degree than whites because they are negative attributes, and blacks are viewed as inferior to whites across all metrics, including the distribution of favorable and disfavorable attributes?

The answer to these very complicated questions can, I contend, be found through an analogy to trademark law. In this analogy, blackness is a product mark that serves to economize on search and information costs among the consumers in the marketplace. The answer also may be

116. One example of a positive stereotype turning into a negative stereotype because it is associated with a minority group may be encapsulated in the experience of Asian Americans in American society. Asian Americans are regarded by some as "model minorities" bccause of their high degree of educational attainment and productivity and the lack of, for want of a better phrase, "problems" they cause in assimilating into American society. See Pat K. Chew, Asian Americans: The "Reticent" Minority and Their Paradoxes, 36 WM. \& MARY L. REV. 1, 24 (1994). What is interesting is how the perceived proclivities of Asian Americans-exceptional aptitude in math and science and exceptional ability on standardized tests such as the SAT and the LSAT-are now creating problems and causing many to view these accomplishments as less than stellar because they are accomplished by Asian Americans. It is illuminating to note that the same tests that are used to designate blacks as intellectually inferior, to defend admissions standards, and to repel affirmative action programs based upon "subjective criteria" are not treated as compelling indicia of ability when the beneficiaries are Asian Americans who perform statistically above their white counterparts. In the situation where minorities like Asian Americans perform better than whites, their accomplishments are minimized in a way that changes a positive into a negative. For example, the existence of quotas limiting the number of Asian-American students admitted to educational institutions has the effect of penalizing Asian Americans for their accomplishments and rewarding whites who, as a group, perform less impressively. See Sclena Dong, Note, "Too Many Asians": The Challenge of Fighting Discrimination Against Asian-Americans and Preserving Affirmative Action, 47 StAN. L. REv. 1027 (1995). At the same time, the standardized tests are still utilized to exclude those who, as a group, perform worse than whites. The winners are, of course, whites who determine what is positive or negative by reference to them. 
found through an analogy to what others have characterized as "extrinsic racism":

One such doctrine we might call extrinsic racism: extrinsic racists make moral distinctions between members of different races because they believe that the racial essence entails certain morally relevant qualities. The basis for the extrinsic racists' discrimination between people is their belief that members of different races differ im respects that warrant the differential treatmentrespects, like honesty or courage or intelligence, that are uncontroversially held (at least in most contemporary cultures) to be acceptable as a basis for treating people differently. ${ }^{117}$

Thus, being black or blackness conveys to the evaluator information that serves as a baseline for determining the worth of the black individual. ${ }^{118}$ The burden then shifts to the black person to dispel or disprove the possession of the attributes that have been improperly assigned to her. This burden is extremely difficult to overcome in contingent relationships, ${ }^{119}$ but may be overcome (at some cost) in longterm relational contexts. ${ }^{120}$

The trademark of black and blackness does a large part of the work-maybe in extreme cases, all the work-in allowing extrinsic racists to make their racist judgments based on their visibly observable

117. APPIAH, supra note 2, at 13.

118. OMI \& WINANT, supra note 53, at 62-63 (using the concept of "amateur biology" to explain differing treatment of and assumptions about individuals based upon the group to which they belong).

119. In this context, a contingent relationship is a one-shot transaction in which the parties are not repeat players or engaged in a long-term relationship that would allow them to obtain information about each other through frequent, long-term contacts. Conversely, a relational relationship is one in which the parties frequently interact and acquire information about each other over time through the interaction. For a discussion of relational versus contingent arrangements im a contractual setting (from whence the terms are derived), see Charles J. Goetz \& Robert E. Scott, Principles of Relational Contracts, 67 VA. L. Rev. 1089, 1091 (1981). Another way of expressing the same idea is to view the contingent relationship as one which occurs either randomly or, if planned, where there are no plans for repeat engagements. Conversely, the relational relationship is one pursuant to which many repeat engagements are planned or viewed as likely to occur in the immediate or near future.

120. In light of the earlier discussion regarding "exceptional or inauthentic blacks," who are separated from their blackness in order to preserve the validity of the mark, see supra note 64 , it is not surprising to discover that although many whites may harbor racist attitudes and beheve in soine or all of the attributes associated with the mark discussed in this section, they also have black friends who do not conform to the attributes conveyed by the mark's designation. This selective dissonance is created because long-term relationships-relational relationships-provide information that is at odds with the self-fulfilling information provided by contingent relationships. The following example is illustrative:

The young construction worker, after offering a litany of grievances, especially in the matter of affirmative action, assures me that the stereotypes of African-Ainericans are true, "I seen "em. They live like low-lifes. Don't like to work. Let their homes run down." He quickly adds, "Oh, the black guys I work with are okay." He speaks of his black friend whom he'd defend against all comers.

TERKEL, supra note 1 , at 5 . 
membership in the black race. To escape the negative effects of racism in American society, we must destroy the trademark of black or blackness, thus forcing extrinsic racists to make independent evaluations of each black individual, rather than relying upon convenient yet erroneous racial stereotypes.

\section{B. Preserving the Mark-The "One Drop of Blood" Rule}

In order to protect the property rights associated with whiteness, American society must preserve the purity of the white trademark and all that it represents. To understand this contention, we inust again turn to the basic principles of trademark law.

One of the primary functions of trademark law is to protect consumers, those who rely on the mark, from deception. ${ }^{121}$ As Summerfield explains:

The consumer may want to purchase a product from a certain source since that source has provided what the purchaser seeks in the product in the past. For the consumer, trademarks are meant to make informed consumer purchases possible and to encourage the maintenance of product quality for the consuuner. ${ }^{122}$

It becomes apparent that, for a trademark to function effectively, the producer must maintain consistent product quality over time, so that the trademark becomes synonymous with the product's characteristics.

The benefits of tradeinarks in reducing consumer search costs require that the producer of a trademarked good maintain a consistent quality over time and across consumers. Hence trademark protection encourages expenditures on quality. To see this, suppose a consumer has a favorable experience with brand $X$ and wants to buy it again. Or suppose he wants to buy brand $\mathrm{X}$ because it has been recommended by a reliable source or because he has had a favorable experience with brand $\mathrm{Y}$, another brand produced by the same producer. Rather than investigating the attributes of all goods to determine which one is brand $X$ or is equivalent to $X$, the consumer may find it less costly to search by identifying the relevant trademark and purchasing the corresponding brand. For this strategy to be efficient, however, not only must it be cheaper to search for the right trademark than for the desired attributes of the good, but also past experience must be a good predictor of the likely outcome of current consumption choices - that is, the brand must exhibit consistent quality. In short, a trademark conveys information that allows the consumer to say to himself, "I need not investigate the at-

121. POSNER, supra note 66 , at 370 .

122. Craig Summerfield, Color as a Trademark and the Mere Color Rule: The Circuit Split for Color Alone, 68 CHI.-KENT. L. REv. 973, 981 (citations omitted). 
tributes of the brand I am about to purchase because the trademark is a shorthand way of telling me that the attributes are the same as that of the brand I enjoyed earlier."

Individuals who rely on the mark of the product are protected in each case from deception because the manufacturer of the product would lose her entire investment in the mark if she reduced the quality of the individual product. This reliance on the mark of the product similarly induces individuals to forego experimentation with other products. Given the uncertainty of quality associated with unfamiliar brands, the consumer may refuse to use other brands and deal with only that brand with which she is familiar.

To determine what, if anything, this has to do with current racial identification and topology, one must take an historical detour and analyze the function of the "one drop of blood" rule ${ }^{124}$ utilized in the United States. The "one drop" rule allowed whites to preserve the mark of whiteness by excluding from that classification all individuals who had less than $100 \%$ white heritage. At one time, when blacks were viewed as less human and less deserving of rights, this rule may have been efficient and appropriate to protect the white consuming public from deception. To allow blacks to classify themselves as whites would work a fraud on the public, thereby undermining the notion of whiteness as a superior mark or product.

This is perhaps the reason that "passing"125 was viewed so harshly by whites at the time when racial differences were reified and legalized. The phenomenon of passing had the effect of undermining the inark of whiteness. It allowed blacks to produce a product, a visibly white person when viewed phenotypically, that had the effect of undermining the product of whiteness, which was defined as the absence of blackness or any black ancestors. ${ }^{126}$ In a world in which passing existed liberally, the ultimate outcome would be the denigration of whiteness as a product because whites could no longer claim that they were different or distinct

123. Landes \& Posner, supra note 68 , at 269.

124. See supra notes $27-28$ and accompanying text.

125. "Passing" refers to a situation where a black individual, due to her light pigmentation, appears white and therefore may "pass" for white in American society despite the "one drop" rule. For a discussion of the phenomenon of "passing," see Harris, supra note 6, at 1710-13.

126.

It is important to note the effect of this hypervaluation of whiteness. Owning white identity as property affirmed the self-identity and liberty of whites and, conversely, denied the selfidentity and liberty of Blacks. The attempts to lay claim to whiteness through "passing" painfully illustrate the effects of the law's recognition of whiteness. The embrace of a lie, undertaken by my grandmother and the thousands like her [who passed as white althougl black under the rule of descent], could occur only when oppression makes self-denial and the obliteration of identity rational and, in significant measure, beneficial.

Id. at 1743 (citations omitted). 
from blacks if (1) they could be produced by black parents or (2) if they could not be differentiated from the offspring of black parents.

In effect, if the "one drop" rule did not exist and racial categories were instead based exclusively upon phenotype and the rule of recognition, ${ }^{127}$ so that if one looks white one is classified as white irrespective of one's parentage or heritage, this would almost completely destroy the allegedly superior mark of whiteness. ${ }^{128}$ This is true because blacks, as producers, would be able to produce a product equal to whites, thus calling into question the base rationale for treating blacks as different or inferior to whites. If blacks can indeed produce whiteness through selective mating, it demonstrates the fallacy of attributing to whiteness any properties other than biologic-those things that constitute the grosser morphology of an individual. Moreover, if racial identification and categorization are biologically rather than socially determined, the social definition of race becomes fluid and meaningless, as it is based solely upon the attributes of grosser morphology, rather than any demonstratable innate characteristics of the individual. ${ }^{129}$

Thus, it is no surprise that the "one drop of blood" rule which serves to severely demarcate the boundary between whites and blacks continues to operate in the United States. This rule is the logical consequence of the historical treatment of blacks who were initially classified as different-that is, less than human when coinpared to whites. The "one drop of blood" rule thus developed as a type of product differentiation in a society in which phenotype could not be trusted to do all of the work of product differentiation. Instead of questioning the value of phenotypical classification schemes, which would ultimately result in the destabilization of both white and black, ${ }^{130}$ American society developed a racial classification scheme that resolved the problem by classifying individuals on the phenotype of the parent or ancestors, even if they were either visibly on the margin or phenotypically white. ${ }^{131}$

Indeed, the "one drop" rule, when combined with the operation and effect of passing, can be viewed as a brilliant development to maintain the trademark of white or whiteness. In most cases, when visual identification is the only information one has to classify another individual, phenotype can be relied on to accomplish the work of

127. See supra note 86 and accompanying text for a discussion of the rule of recognition.

128. See Landes \& Posner, supra note 68 , at 270.

129. APPIAH, supra note 2, at 35-37 (using an analysis of genetic differences to support his argument that race is unimportant in explaining biological differences between people).

130. See infra notes 188-205 and accompanying text for a discussion of the benefits of destabilization.

131. See supra notes $27-28$ and accompanying text. 
classification. This is both easy and efficient. When one sees an individual who is phenotypically white and who is a stranger to the person doing the classification, placing that individual in the "white box" is the natural and logical outgrowth of the classification scheme. Moreover, it is efficient because one does not have to do any investigative work in order to determine how to racially classify the individual. Requiring the individual to do otherwise would severely undermine the inark of whiteness, because whiteness would have to be verified through the transmission of infornation from the individual being classified to the classifier.

However, in the situation where the individual doing the classifying has independent and verifiable data about the actual parentage or ancestry of the person being classified, that data becomes relevant and viable. Such information about the relevant product can be taken into account to assess the worth of the product. To do otherwise would allow phenotypical classification to do all the work. This would, once again, ultimately undermine whiteness as a product since it could knowingly be produced by blacks. As a result, coupling the "one drop" rule with passing is a highly cost-efficient mechanism for preserving the trademark of whiteness. When phenotypical observation fails to identify a black individual, that person will still be excluded from the white category so long as there is some independent evidence of her black parentage. At the same time, the system allows enough fiuidity so that the marginal case of a visibly white person who happens to be the product of black parents does not serve to undermine the efficiency of the classification scheme by requiring all whites to prove parentage or other indicia of whiteness in order to protect the mark. ${ }^{132}$

Consequently, the "one drop" rule accomplishes both product definition and differentiation in an attempt to preserve the mark of

132. The appropriate analogy is to counterfeiting and the protections taken or not taken to protect the integrity of currency. Clearly, the costs of precautions designed to ferret out every counterfeit bill outweigh the benefits of using a visually verifiable currency. Thus, merchants are not equipped with scanners that would automatically catch every counterfeit bill because the transaction costs of doing so outweigh the loss incurred by doing nothing. Allowing some marginal amount of counterfeiting is pareto optimal. On the other hand, if one has actual knowledge of the counterfeit status of currency, however acquired, one has a duty to remove it from circulation when requested to do so by an agent of the Treasury Department. A failure to acquiesce to such a request may result in criminal liability for the holder of the counterfeit bill. See 18 U.S.C. $\S 492$ (1995). The same can be said for racial classifications: the costs of determining the race of an individual other than by casual "eyeballing" is prohibitive and societally counterproductive. However, if one has knowledge that an individual is a "counterfeit" white due to black parentage, one has a duty to remove it (the person) from circulation among whites. Of course, what we are addressing, both with respect to currency and racial identification, are individuals on the margin. Very few people would accept a red $\$ 20$ bill with a picture of George Washington Carver on its face, just as few people would accept the notion that someone who is phenotypically black, such as Justice Clarence Thomas, is white. It is only on the margin that efficiency allows passing and counterfeiting to exist. 
white and whiteness in American society. The only problem with this scenario is that the product is people, and the alleged differences between the people are erroneous and misguided. ${ }^{133}$ The "one drop" rule defines and differentiates products where no true differences exist. The rigidity of the "one-drop" rule, by which one is classified as different or "other" based on one drop of black blood, can only be explained as an attempt to maintain product quality. Because it is impossible to define what level of blackness constitutes an inferior product, anyone who is part black, no matter how minuscule, has to be treated as different from or inferior to a white individual. To do otherwise would not only encourage miscegenation, but also undermine the property value inherent in whiteness.

As a result, the "one drop" rule serves two additional functions. First, since no threshold can be established to demonstrate how much blackness equals inferiority or subordination, any percentage-one drop of blackness will do it ${ }^{134}$ - serves to create a stable trademark in black and blackness based not on superior quality but on inferior quality. This particular mark of black and blackness is not a mark promoted by the group or manufacturer to self-identify and establish product quality; rather, this erroneous and inefficient mark is imposed on those associated with the mark by its "competitors"-those who stand to gain from the perception of the lessened quality of the mark. The competitors, whites, stand to gain when the quality of the black mark is viewed as consistently inferior. Whites, acting as a firm or a group and in control of the marketplace, have an incentive to maintain their strong mark by weakening the mark and the quality associated with the mark of black and blackness.

This leads to the second and related point. Whiteness and the values associated with it are threatened to the extent that there are blacks who do not fit the inferior attributes of the mark of blackness. These exceptional blacks, who outperform the stereotypes or attributes associated with the mark of blackness, threaten to undermine the stability of the inferior mark of blackness, just as an inferior product would undermine the overall superior trademark for that product. With products, the consumer who purchases the inferior product will no longer rely on the superior reputation of the mark, and the firm will suffer a loss in its investment.

Putting both points together, the analogy in the literature on trademarks is as follows:

[A] firm's incentive to invest resources in developing and maintaining (as through advertising) a strong mark depends on its

133. See supra note 94 and accompanying text.

134. See supra note 28 and accompanying text. 
ability to maintain consistent product quality. In other words, trademarks have a self-enforcing feature. They are valuable because they denote consistent quality, and a firm has an incentive to develop a tradenark only if it is able to maintain consistent quality. To see this, consider what happens when a brand's quality is inconsistent. Because consumers will learn that the trademark does not enable them to relate their past to future consumption experiences, the branded product will be like a good without a trademark. The trademark will not lower search costs, so consumers will be unwilling to pay more for the branded than for the unbranded good. As a result, the firm will not earn a sufficient return on its trademark promotional expenditures to justify making them. A similar argument shows that a firm with a valuable trademark would be reluctant to lower the quality of its brand because it would suffer a capital loss on its investment in the trademark. ${ }^{135}$

In a perverse way, race and racial identification serve the same function in current society. For example, one phenomenon that $I$ have written about recently involves the characterization of "The Best Black."136 As Professor Carter discussed, the black who excels far above the racially defined expectations of the white observer or participant is cast in the light of "The Best Black." In other words, that black is treated as the exception that startles or surprises the white evaluator in that this black does not conform to the evaluator's racially defined expectations. ${ }^{137}$ What is interesting about the phenomenon of "The Best Black" syndrome is how best blacks are separated from their blackness in an attempt to preserve the characteristics of the trademark of blackness. ${ }^{138}$ Thus, "The Best Black" is often lauded for attributes that are the antithesis of her blackness in an attempt to explain why the individual black succeeded. A "Best Black" often is described as one who is not like other blacks or as one who had a father who was a college professor and was educated at the best schools (with whites). "The Best Black" is a surprise to whites because she does not conform

135. Landes \& Posner, supra note 68, at 270.

136. Alex M. Johnson, Jr., The New Voice of Color, 100 YALE L.J. 2007, 2009, 2012-15 (1991) (discussing Stephen L. Carter, The Best Black, and Other Tales, 1 Reconstruction 6 (1990)).

137. Stephen L. Carter, The Best Black, and Other Tales, 1 Reconstruction 6, 7-9 (1990).

138.

As Omi and Winant reveal, we also experience a crisis of racial meaning when "people do not act 'black,' 'Latino,' or indeed 'white.' The content of such stereotypes reveals a series of unsubstantiated beliefs about who these groups are and what 'they' are like." In our everyday experiences, we do not simply employ racial categories to signify physical differences, but invoke an entire array of beliefs and judgments about the nature of those so designated.

Lee, supra note 95 , at 762 (quoting OMI \& WiNANT, supra note 53, at 62). 
to the mark that is associated with blackness. That nonconformity challenges the information provided by the mark.

In order to preserve the negative trademark of blackness despite the existence of the "Best Black," this outstanding individual is deemed atypical and is "fenced off" from the rest of black society. This has the effect of preserving the negative attributes of the trademark because the good qualities or attributes that caused the individual to be characterized as "The Best Black" are either associated with the individual's ties to whites or whiteness, or attributed to rare attributes that other blacks do not possess. Indeed, it is the rarity of the attributes possessed by "The Best Black" that causes the individual black to be regarded as "The Best Black" in the first place.

Consequently, a black person who exceeds in a venue other than sports or the arts is not regarded as truly black. ${ }^{139}$ Rather, that person's success or skill is separated from her blackness and ascribed to some other source, such as her ties to the white community. If all else fails, the individual is regarded as the exceptional, the novel, the rarity that cannot be explained or rationalized (similar to an idiot savant). The individual, however, is never regarded as a black who succeeds as a result of his or her blackness; to do so would have the effect of destroying the negative attributes of the mark that are associated with race.

Similarly, one cost of affirmative action is that it maintains to some extent the negative attributes of the racial trademark and its connotations as it relates to blacks. Stephen Carter has correctly noted that one major difficulty created by the use of race-based affirmative action plans is the denigration of the achievements of all blacks who will, rightly or wrongly, have their successes and attainments attributed to affirmative action rather than merit. ${ }^{140}$ Affirmative action, then, serves the same purpose as "The Best Black" syndrome, because it allows others to belittle the accomplishments of blacks by attributing their success to non-merit-based factors. ${ }^{141}$ Because it is presumed and accepted that without affirmative action, blacks cannot compete successfully with whites, American society is able to preserve the inferior

139. For a discussion of why blacks excel in these areas in disproportionate numbers, see Johnson, supra note 5.

140. CARTER, supra note 75, at 24-27, 47-52.

141. As noted, one cost, which I believe to be a small one, of affirmative action is to allow whites to denigrate the accomplishments of all blacks. That cost, although recognized, does not, however, outweigl the benefits generated by affirmative action. Elsewhere 1 have attempted to defend the use of affirmative action by fully discussing the benefits and costs engendered by its use. See Alex M. Johnson, Jr., Defending the Use of Quotas in Affirmative Action: Attacking Racism in the Nineties, 1992 U. ILL. L. REv. 1043. I also present this same defense of affirmative action, from what I characterize as a different, even "twisted," perspective, in Johnson, supra note 5. 
characteristics of the black mark even in the face of meritorious accomplishments by blacks.

\section{Destabilizing the Mark}

As I have argued above, the positive trademark of white or whiteness and the negative trademark of black or blackness do not accurately correspond to the traits and characteristics of individuals comprising these groups. For this reason, the trademarks of whiteness and blackness should be destabilized.

In re Owens-Corning Fiberglas Corp.$^{142}$ provides a useful analysis of the grounds for affording trademark protection to a certain product characteristic and the means by which that trademark protection may be destabilized. In Owens-Corning, the federal court faced the complicated question of whether to afford trademark protection to the color pink, which was used by Owens-Corning to advertise its insulation product. Prior to the decision in Owens-Corning, courts had employed the "mere color rule" to deny registrability to color. ${ }^{143}$ This rationale for denying registrability was based on two considerations: (1) there was a concern that allowing colors to be registered would eventually result in the depletion of the available stock and ultimately be anti-competitive, and (2) there was an additional concern that "trademark infringement suits would soon denigrate into questions of shade confusion that the judiciary is ill-equipped to resolve."144 Breaking with tradition, the federal court in Owens-Corning held that color alone can be registrable as a trademark under the Lanham Act. ${ }^{145}$

Owens-Corning wanted to register the color pink as a trademark for its fibrous glass residential insulation because it claimed that it had acquired a secondary meaning worthy of protection by the Lanham Act. ${ }^{146}$ As Owens-Corning indicates, trademark protection is efficient and viable only when there is a viable product which can and should be differentiated from the other products in the marketplace. The protection provided by the Lanham Act $^{147}$ is inefficient, however, when the product's value is defined solely by the connotations of the mark, rather than by some independent characteristics associated with the

142. 774 F.2d 1116 (Fed. Cir. 1985).

143. See Summerfield, supra note 122, at 974 n.7.

144. Jeffrey M. Samuels \& Linda B. Samuels, Color Trademarks: Shades of Confusion, 83 TRADEMARK REP. 554, 555 (1993).

145. Owens-Corning, 774 F.2d at 1122 (noting that "[t]he color of goods... may serve as a trademark if the statutory requirements are met"). For a brief history of the codification of federal trademark law, see Samuels \& Samuels, supra note 144, at $554 \mathrm{n} .1$. For purposes of this Article, it is sufficient to note that the Lanham Act was enacted in 1946 as 60 Stat. 427 and is currently codified in 15 U.S.C. § 1051 et seq. (1996).

146. Samuels \& Samuels, supra note 144 , at 555-56.

147. 15 U.S.C. § 1501 et seq. (1996). 
product that the mark describes. Thus, if the mark alone lends an air of separateness to a product which is otherwise similar to all other products in the market, the mark is deceptive and inefficient and should not receive legal protection.

As I have discussed at length in Part II.A, apart from the variances in the grosser morphology of individuals, upon which nothing substantive should turn, there are no significant biological differences between individuals of different races. However, due to racism and the effects of the "one drop" rule, the trademarks of whiteness and of blackness, which would never survive in an economically rational market, have flourished in America's social forum. Thus, these trademarks, which preserve the property rights represented by the white mark, should be destabilized.

Under trademark law, the attributes associated with a particular mark can be changed or destabilized in two ways: (1) by improving the quality of the mark, or (2) through the process of "shade confusion." ${ }^{148}$ Under the first principle, the negative mark of blackness could be destabilized by taking steps to improve the mark's quality. Although relatively rare, it is not impossible for a producer to take a mark that is associated with poor quality and negative attributes and to transform that mark into a superior mark that is associated with a superior product. ${ }^{149}$

Indeed, one example of an attempt to improve the quality of the mark of blackness is evidenced by the "Black is Beautiful" movement in the 1960s and 1970s. ${ }^{150}$ This movement attempted to improve the self-image of blacks by embracing blackness as a positive, enriching, or ennobling attribute-a positive mark of blackness. This movement, which focused largely upon changing the characteristics of the black mark, can be viewed not only as an attempt to instill black pride, but also as an attempt to convince whites, as well as blacks, that the negative characteristics which they associate with blackness are erroneous.

Employing multi-racial categories will not detract from the continuing efforts by blacks and others to dispel the negative attributes of the mark as erroneous, racist stereotypes having no foundation in

148. For further discussion of shade confusion, see Samuels \& Samuels, supra note 144, at 56870; Summerfield, supra note 122, at 991-94.

149. One case in point would be how Japanese products, particularly elcctronic equipment and cars, historically have been viewed by the American consumer. In the 1960s and 1970s, Japanese products were viewed as cheap and inferior. However, in the 1980s and 1990s, as evidenced by our burgeoning trade deficit, Japanese products in electronics, consumer goods, and automobiles have been viewed as of the highest quality. By upgrading the quality of their products, Japanese manufacturers were able to overcome a "negative" mark and establish a "positive" mark. See David Aviel, Why the United States Isn't Winning the Trade War with Japan, INDus. MGMT., Mar. 1990, at $14,16$.

150. This movement was also signified by the phrase, "l'm Black and l'm Proud." 
fact. Blacks who identify themselves as blacks will contimue to exist and continue to use blackness as a racial category. Hence, attempts to rehabilitate or correct the mark are necessary and appropriate. By adopting a multi-racial taxonomy, I am therefore not advocating that blacks and blackness disappear. I do contend, however, that a benefit will be gained by using both methods of improving the mark. Thus, efforts to improve the quality of the current mark of blackness must continue.

In addition, the second method of destabilizing the mark, shade confusion, should also be utilized. By that I mean that new products associated with new marks should be introduced into the stream of racial discourse to continue to destabilize and weaken the perceptions generated by the old mark. Once again, an analysis of Owens-Corning is revealing. Shade confusion is often asserted to preclude registration of a color, because it is clained that consumers will be confused by slightly different shades or hues of registered marks and therefore would not be in a position to distinguish between, say, the pink that is registered by Owens-Corning and the shade of pink used by Sweet ' $N$ Low in the packaging of its product. ${ }^{151}$ If a color is incapable of being regarded as a unique mark or attribute because of shade confusion, it is not capable of registration. Conversely, if a color is capable of registration, a competing product that deploys a color that is similar to the trademarked product's color and, consequently, engenders shade confusion would be infringing upon the mark..$^{152}$

What I hope to accomplish with the destabilization of racial categories is the equivalent of shade confusion. Shade confusion is, of course, to be avoided in the world of trademark law. However, when, as in the case of race, categories have been created that serve no real purpose in identifying the characteristics of individual products, shade confusion is an appropriate tool for rendering these categories useless to the consumer. In a world with an infinite number of colors or racial classifications, shade confusion is easily attainable. At some point, a very light criinson begins to look very similar to a "pure" pink, although they are each distinct. 'That distinctiveness may only be apparent if the colors are compared very closely. ${ }^{153}$

151. Of course, with this hypothetical there is no product confusion because artificial sugar products are not often confused with insulation. Perhaps a better example would be a hypothetical insulation manufacturer that used a very hight crimson, resembling Owens-Corning's pink, in its product advertisements.

152. Summerfield, supra note 122 , at $991 \mathrm{n} .164$.

153. Color confusion differs from a situation involving misappropriation of the same color by a competing manufacturer of Owens-Corning's insulation products. Using the same color, if trademarked, violates the Lanham Act, which seeks to make investment in the mark profitable by prohibiting such imitations. See supra notes $145-147$ and accompanying text. However, by preventing shade confusion, we seek not to protect a property right of the producer, but rather to 
If race is destabilized so that multiple categories of "color" develop, it is my contention that it will create a situation in which the equivalent of shade confusion abounds. The current racial classification scheme is able to avoid shade confusion by employing bipolar racial categories of whites and nonwhites. There is no in-between. Thus the consumer never confuses the products, and the classification schemes, although patently erroneous, appear efficient.

In a world in which a multiplicity of racial categorizations abounds, racial identification becomes more difficult, more time-consuming, and more error-prone. People today largely tend to discriminate based on what they see and observe, which is, in turn, based on visual or other inputs (the "interpretivist" model of discrimination). ${ }^{154}$ To a large extent, much discrimination is self-generated, in that no information or communication need be made or attempted between the party being discriminated against (the "discriminatee") and the one doing the actual discriminating (the "discriminator"). Discrimination will occur as a result of the interaction of what is observed and interpreted by the discriminator and the prejudices, predilections, and stereotypes held by that individual coupled, in most situations, with a hierarchical ordering or preference that has been historically or socially established. ${ }^{155}$

However, by destabilizing dichotomous racial categories into a multitude of racial classifications, interpretivist discrimination becomes inefficient and time-consuming. To illustrate, if the discriminator is uncertain whether an individual is black, white, or mulatto, that individual, before acting in a discriminatory fashion, must obtain additional information (which can be costly or impossible given the

reduce the search costs imposed on consumers in disceming the identity of the products associated with the mark. The value of a trademark is the saving in search costs made possible by the information or reputation that the trademark conveys or embodies about the brand (or the firm that produces the brand). With shade confusion, a consumer can ultimately determine that the marked product differs from that competitor's similar-looking product, but only at a significant cost (e.g., by procuring both products and making an extensive comparison) which would largely defeat the economic benefits, at least as they pertain to search costs, inherent in the mark.

154. The manner by which discrimination operates both legally and factually in American society is beyond the scope of this Article and forms the subject for another paper 1 am currently working on, entitled Homosexuals, Mulattos and Religious Differences: Invisible Differences that Threaten [hereinafter Johnson, work in progress] (on file with author). For a discussion of how racial categorization by the courts operates, see Kenneth L. Karst, Myths of Identity: Individual and Group Portraits of Race and Sexual Oriemtation, 43 UCLA L. REv. 263 (1995).

155. This is not to say that discrimination runs one way from the dominant (white) over the subordinate or oppressed (black, brown, etc.). Blacks and other minorities are also capable of engaging in discriminatory behavior towards whites and, more frequently, towards other minority groups. See Reginald L. Robinson, "The Other Against Itself": Deconstructing the Violent Discourse Between Korean and African Americans, 67 S. CAL. L. REv. 15 (1993). For the sake of discussion, however, I wish to typify the experience so that it more closely reveals the type of discrimination that is the most pernicious and harmful: race discrimination in which a prejudiced white discriminates against a black person simply because she is visibly black. 
situation) or run the risk of making the wrong categorization and incurring error costs. Thus, any discrimination under a scheme of multiple racial categories is, by definition, conscious, time-consuming discrimination.

This second type of discrimination, denominated "intentionalist," is based on a heuristic in which the discriminator cannot simply act or rely on visual inputs or data that she controls in determining whether to produce the discriminatory behavior. Instead, the putative discrimmator must rely on other information, gleaned either from third parties or the putative discriminatee, in order to make the determination to act in an impermissibly discriminatory manner. Of course, such information is highly costly and to some extent depends upon the discriminatee's willingness to provide it.

Although intentionalist racism will persevere to some extent in a world of multiple racial categories, interpretivist discrimination will largely decrease..$^{156}$ Indeed, I' contend that the increased error and information costs naturally resulting from multiple racial categories would eventually lead to a diminution in the importance of race, and ultimately, to its elimination as a socially relevant identifying characteristic. To some extent race hopefully would be regarded like hair color or eye color or one's religious affiliation; something that is interesting and informative but upon which nothing substantive turns. ${ }^{157}$ In this respect then, race ultiunately would give way to ethnicity as a vehicle for group identification. ${ }^{158}$ Just as one's ethnicity is sometimes but not often visible, ${ }^{159}$ nor often perfectly accurate as an identifier or

156. In this regard, I argue that the legal system should not treat discrimination based on the intentionalist model the same as discrimination based on the interpretivist model. Rather, intentionalist discrimination should be treated more harshly because what is being chilled under the intentionalist model is the equivalent of protected speech and conduct. By contrast, discrimination that arises from the same model, e.g., sexism and racism, which are both forms of interpretivist discrimination, should be treated similarly. The legal system's current distinction between these types of discrimination, affording racial classifications strict scrutiny and gender classifications only intermediate scrutiny, is therefore erroneous. See Johnson, work in progress, supra note 154.

157. See Richard A. Wasserstrom, Racism, Sexism, and Preferential Treatment: An Approach to the Topics, 24 UCLA L. REv. 581,586 (1977).

158. For a definition of ethnicity and a discussion of the role it should play in supplanting race as a socially acceptable eategory of identification, see infra Part III.

159. Whether one is Irish, Polish, or Italian may, in rare cases, be easily verifiable. Thus, to conjure up other stereotypes, a beefy, hearty, florid, red-hcaded male participating in the St. Patrick's Day Parade in Chicago wearing a grcen bowler may be easily identified as an Irishman. Similarly, a dark-haired feniale, who, although visibly white, has a dark complexion with an aquiline or "Ronian" nose, may be easily identified as Italian (especially if that person is a waitress in an Italian restaurant in Little Italy in New York and has a name tag that reads Calabresi). Although in a few instances an individual's ethnicity may be visually ascertainable absent communication, I personally find it difficult if not impossible to presuppose someone's ethricity without the types of visual clues suminarized above. Thus, I cannot even begin to describe what a stereotypical Polisl person looks like and how I would pick that person out from a line-up that includes German, Irish, and Italian members. Of course, if I was told that person's name was Dzienkowski, like my former colleague 
categorizer, race would likewise be submerged so that it would not be ascertained by simply looking at or observing another individual.

More importantly, in a world in which a multiplicity of racial categories exists for the identification of the race of individuals, "black" as a racial definition will be defined positively as an ethnic identification designated "African American."160 When not all persons who have some visible African ancestry in their genetic base are identified as black in terms of a black racial group, then those individuals who can trace their ancestry and genes solely to blacks who forcibly or voluntarily emigrated to America will be able to proclaim with pride their undiluted blackness. ${ }^{161}$ Rather than being a negative classification, black and blackness will become a positive, ennobling categorization or classification that means the absence of white, just as whiteness means the absence of black. Balance, then, is achieved in racial identification by recognizing an entire spectrum of races based on the miscegenation that has occurred throughout this country's history. Unity is also achieved between those blacks who lack any white

and friend from the University of Texas, I might guess his Polish heritage and ancestry. An audible clue, such as being told an individual's last name, would, however, violate my "no communication" rule. Under such restrictions, the ethnic category, standing alone, becomes virtually indeterminate. By contrast, a racial category is both visually identifiable and geographically indeterminate in nature. Thus, in a lineup, I would not choose a visibly African person as a member of either an Italian, Polish, German, or Irish ethnic group. However, these automatic assumptions are ridiculous given the fact that there are blond Italians, dark Irish (sometimes referred to as black Irish), dark Germans, and Polish persons with short or anglicized names. Similarly, there are no doubt Africans who have emigrated historically to Italy, Poland, Ireland, and Germany, and who should be properly classified as members of those respective ethric groups. Although ethnic classifications may do somc work in segregating people based on factors that some may deem important, they are not infallible. Indeed, I argue that the determination of ethricity can only be made fool-proof if information other than that provided by visual acuity is gleaned from or about the individual sought to be categorized. See infra notes 174-176 and accompanying text. That makes the use of ethnicity very different from the use of racial categorizations and something that should be encouraged for the positive reasons that are associated with ethnicity, rather than the negative ones associated with race. See infra Part III.A.2.

160. I discuss the ethnic group I have denominated African American in Part Ill.C., infra.

161. Indeed, this may already be happening to some extent, based on anecdotal evidence. By that I mean, Africans who have recently emigrated to America and who are visibly and solely black are treated, according to my students in Critical Race Theory, differently, that is, better than American blacks. I surmise that this is likely because American blacks face established negative stereotypes not identified with African blacks. It would seem then that the stereotypes or extrinsic racism that American blacks labor against are not purely race- based, but also culturally or environmentally based. Whites may assign negative attributes to American blacks that they do not assign to African or European blacks, based upon the belief that all American blacks grow up in crime-ridden ghettos where drugs, wanton sex, and illegitimacy are the norm. This phenomenon of foreign blacks being treated more positively than home-grown blacks, which as far as I know, is unproven scientifically, could and should lead to a "reverse" passing phenomenon. For a discussion of passing, see supra notes 125-129 and accompanying text. As a consequence, instead of passing for white if their pigmentations is light enough, blacks may pass for European blacks if they lack pigmentation, or for Africans if they have dark pigmentation. 
ancestors, mulattoes, and other mixed-race issue by recognizing that they belong to the same ethnic group-African Americans.

Destabilizing the marks of "black" and "blackness" will have a liberating effect on those previously classified as blacks who have internalized the supremacy and metric of whiteness as the mediating value in determining the worth of an individual based on skin color. ${ }^{162}$ The most efficacious vehicle for the eradication of racism is simply to eradicate the tradeınarks of black and blackness currently defined in terms of what they are not-white. Embracing a multi-racial categorization scheme eliminates the negative attributes associated with the trademarks of black and blackness and destabilizes the positive attributes of the tradeinarks of white and whiteness.

The risk, of course, is that the recognition of many races, such as a mixed-race or mulatto category, will have the effect of solidifying the Color Consciousness that I am seeking to diminish and eradicate. Conceivably, an argument could be made that those products of a mixed-race union who are identified as mixed-race will be beneficiaries of better treatınent than those identified as purely black, if such a category remains in use. ${ }^{163}$ However, this should not occur unless whiteness remains as a mediating and subordinating principle in the classification of minorities. By supplanting ethnicity for racial identification, I contend that such a risk can be avoided if not eliminated entirely.

\section{III}

\section{Embracing an EThNic Paradigm For African Americans}

\section{A. A Theory of Ethnicity}

Throughout the text I have maintained that once racial categories are destabilized, ethnic categories will rise in their place as a positive, unifying classification system. To understand this contention, I must first make explicit the difference between race and ethnicity that is so often conflated by others. ${ }^{164}$

162. Njeri, supra note 56 , at 16 (discussing Alice Walker's theory that blacks cannot progress unless they refrain from "colorism").

163. In order to avoid confusion with the old trademarks of black and blackness, defined largely by the "one drop" rule, it is beneficial to use some other term to refer to those individuals who wish to be identified as purely black, that is, without white ancestry. 1 prefer the term "Ebony American," because Ebony contains none of the negative connotations associated with black and blackness. For the negative connotations associated with black and blackness, see supra notes 74-84 and accompanying text.

164. For an example of the conflation of race and ethnicity, consider the following passage by Thomas Sowell:

Lest the word "race" in the title of this book lead to misunderstanding, or to quibbling, the term is used in the same general sense in which it has been used in my earlier writings, dating back to Race and Economics: "The term 'race' will be used here in the broad social 
Omi and Winant offer the following description of race as it was construed prior to the advent of the twentieth century:

Whites were considered the superior race; white skin was the norm while other skin colors were exotic mutations which had to be explained. Race was equated with distinct hereditary characteristics. Differences in intelligence, temperament and sexuality (among other traits) were deemed to be racial in character. Racial intermixture was seen as a sin against nature which wonld lead to the creation of "biological throwbacks." These were some of the assnmptions in social Darwinist, Spencerist and Eugenicist thinking about race and race relations. ${ }^{165}$

Thus, as defined, racial categories largely correlated with the grosser morphology of the individual and almost exclusively described intellectual and physical attributes.

By contrast, the definition of ethnicity almost completely excludes the grosser morphology of an individual, focusing instead on other, highly variable characteristics.

In contrast to biologically oriented approaches, the ethnicity-based paradigm was an insurgent theory that suggested that race was a social category. Race was but one of a number of determinants of ethnic group identity or ethnicity. Ethnicity itself was understood as the result of a group formation process based on culture and descent. "Culture" in this formulation included such diverse factors as religion, language, "customs," nationality and political identification. "Descent" involved heredity and a sense of group origins, thus suggesting that ethnicity was socially "primordial," if not biologically given in character. While earlier theorists did indeed assume this, later ethnicity theory caine to question the validity of any primordial sense of identity or attachment, arguing instead that these concepts too were socially constructed. ${ }^{166}$

Although the ethnic-based theory of classification existed in the United States as early as the 1920s and 1930s, it has largely, if not exclusively, been applied only to those who would be racially classified as white. ${ }^{167}$ Other racial groups, as they are socially constructed by

sense in which it is applied in everyday life to designate ethnic groups of various sorts-by race, religion, or nationality.". .

Because this study focuses more on social realities, rather than on biological realities, it defines racial or ethnic groups primarily in social rather than biological terms.

Sowell, supra note 60 , at xiii (citation omitted).

165. OMI \& WINANT, supra note 53, at 14-15 (citation omitted).

166. Id. at 15 (citations omitted).

167.

Insurgent ethnicity theory's main empirical reference point had been the study of immigration and the social patterns resulting from it. [Robert. E.] Park and his student Louis Wirth saw the development of ethnic enclaves and what Park called a "mosaic of 
society, can never truly achieve an ethnicity that is separate from their racial identification. ${ }^{168}$ The two become one. This is particularly true for the American black. ${ }^{169}$ American blacks are confined to one group in society regardless of whether they are from the deepest, most rural South and are descendants of sharecroppers, or if they hail from the most urbanized, Northeastern city and are descendants of professionals who can trace their heritage to recent Canadian immigrants. Consequently, it must be recognized that within the ethnic-based theory currently employed in the United States is a biological theory of racial formation im which white supremacy is, to a degree, exalted by the recognition of ethnic differences, while those who are not white and European continue to be classified based on race.

\section{Ethnicity as a Flexible/Mutable Characteristic}

I maintain that minority racial groups have been denied ethnicity largely because ethnicity, as compared to race, is a positive category which offers empowering benefits to the classified group with little or no corresponding costs. ${ }^{170}$ One of the primary benefits gained from ethnic categories, but not available under racial categories, is the ability to embrace or to reject the category at will. Racial classification is based largely upon visual observation. A classifier is able to racially categorize others on the basis of visual inputs she receives, with little or no active involvement or imteraction with the person being

segregated peoples" as stages in a cycle leading to assimilation. [Horace] Kallen's perspective, by contrast, had focused on the acceptance of different immigrant-based cultures. But both assimilationism and cultural pluralism had largely emphasized European, white immigrants, what Kallen called "the Atlantic migration." The origins of the concepts of "ethnicity" and "ethnic group" in the US, then, lay outside the experience of those identified (not only today, but already in Park's and Kallen's time), as racial minorities: Afro-Americans, Latin-Americans, Native Americans and Asian Americans (blacks, browns, reds, and yellows). The continuity of experience embodied in the application of the terms of ethnicity theory to both groups - to European immigrants and racial minoritieswas not established; indeed it tended to rest on what we have labeled the immigrant analogy.

Id. at 16-17 (citations omitted).

168. Cf. id. (discussing how the the origin of the concept of ethnicity lies outside the experience of those identified as racial minorities).

169. 1 highlight "American black" because of the assertion, addressed supra at note 161 and accompanying text, that blacks from other countries are treated differently, that is, better than American blacks. That fact may reflect the reality that foreign-born blacks, like white Americans, may have an ethnic identity based on their ancestry and nationality that American blacks do not have.

170. As detailed below, ethnic rather than racial identification is beneficial to minorities, because ethnicity is a flexible/mutable characteristic that can be better controlled and policed by the individual subject to the negative classification that results from the identification. However, one should not lose sight of the fact that ethnicity per se is a very valuable form of group identification providing many benefits to the classified group. See JANET T. LANDA, Trust, ETHNicity, AND IDENTITY 16-17 (1994) (citing EthNIC Groups AND BouNDARIEs (Fredrik Barth ed., 1969)) and infra text accompanying note 184 . 
categorized. ${ }^{171}$ Of course, the classifier need not physically observe the individual to employ racial classifications. Having learned the racial classification of an individual, the classifier is able to immediately draw a mental picture of that individual even though she has never met the individual. Because race is biologically/phenotypically determinable, the party being categorized has little or no control over this process of categorization.

Moreover, due to the manner in which race and racial identification is socially constructed, American society has created a binary construction of race, with white and other, that relies on phenotypical observation for categorization. Because racial categorization relies on typology based on the identification of blacks by their grosser morphology, ${ }^{172}$ it cannot be concealed, nor is it a fluid categorization, as it is in other societies, such as Brazil, ${ }^{173}$ that transcend identification based on grosser morphology. By destabilizing racial identification and supplanting it with ethnic identification, one stable inflexible categoryrace and racial identification-will be replaced with a fiuid category that does not rely on visibly observable traits characterized as grosser morphology. Thus, although an individual may still be able to classify another individual based on her grosser morphological characteristics, which are not malleable or concealable, the information imparted by such characterization will have little or no significance in a society in which ethnic identification supplants racial identification, because the characterization based on grosser morphological traits will not convey any information regarding ethnicity.

Unlike race, ethnic identification can be shed and transformed when necessary. Ethnic identification is learned and not visual. It is a characteristic that must be communicated from the ethnic group member to the individual doing the categorization. ${ }^{174}$ In this respect, ethnicity is different from race because race is something that is typically visibly ascertainable and recognizable without the need for or use of any communication from the party being categorized to the party doing the categorization. ${ }^{175}$ What that means is that if ethnicity is something that is learned and communicated, it is something that can be

171. This type of discrimination, which I term "visually-induced," is discussed supra at notes 1011 and accompanying text.

172. See supra note 2 and accompanying text.

173. See supra notes $42-44$ and accompanying text.

174. For a discussion of why this is so, except perhaps on the margin where ethnic identity is visible and serves a function similar to that of race, see supra note 159 and accompanying text.

175. Race cannot be manipulated, except for those limited cases of "passing" in which blacks are able to pose as whites due to their seemingly white features. For a discussion of "passing," see Harris, supra note 6, at 1710-15, 1765-66, and supra note 125 and accompanying text. This concept of "passing" demonstrates the futility of racial classification schemes premised on grosser morphology and reinforces the claim that ethmicity, not race, should govern categorization. 
changed, concealed, or disguised. Historically, ethnicity became the vehicle of assimilation for white ethnic groups into the American melting pot. As members of a white ethnic group, Jews, Irish, Poles, and Italians initially were able to suppress their ethnicity by anglicizing their names and features and entering into mainstream Anglo-Saxon culture.

Even if an ethnic identity were afforded to blacks, it is not immediately clear that blacks could benefit from the malleable nature of ethnic categories. Being construed by others as black, brown, or yellow is quite different from being construed by others as Polish, Jewish, or Lithuanian. One important difference is that with respect to the categorization of an individual who is black, brown, or yellow, that categorization is made by visual identification based on those aspects called the grosser morphology, i.e., hair, skin, and bone structure. By contrast, ethnic identification of whites typically takes place only when information is given by the individual being categorized to the categorizer. ${ }^{176}$

Despite this difference, I still maintain that an ethnic identity can provide some anonymity to those otherwise classified by race. This is illustrated by the unique treatment of Hispanics in American race relations. Under the current Census Bureau definition, a person who desiguates himself or herself as Hispanic may be of any race. ${ }^{177}$ Consequently, a person whose phenotype would characterize him or her racially as white, black, Asian, or Native American may be considered an Hispanic.

In this sense, the ethnic term "Hispanic" provides a flexible classification for those who otherwise would be locked into an inflexible racial category. Unfortunately, the classification of Hispanic has recently begun to have a racial meaning in American society, which, given this country's definition of race, means those who are not white..$^{178}$ In particular, it may mean those who are mestizo, black, or other, but, in any event, they are conclusively not white.

I contend that the "racial category" of Hispanics is developing and gaining strength because whites refuse to recognize the product of mixed unions-mestizos-as white. Whites want to prevent shade confusion by rejecting the ethnic definition of Hispanic in favor of the

176. On the margin, of course, both of these statements are too broad. Those who are black under the rule of descent rather than the rule of recognition and those who visibly display their ethnicity by the type of garb they wear are exceptions to the general rules that 1 have just posited.

177. But see Holmes, supra note 8, at A18: "In addition, the Government is considering changing Hispanic from an ethnic designation to a racial one since so many people say they view being Hispanic as a separate race."

178. See supra note 18. In addition, the National Council of La Raza appeared before a House Committee on the Census in June of 1993 and demanded that the ethnic identification of Hispanics on the Census be replaced by a box representing racial identification. See Hanna Rosin, Boxed In: America's Newest Racial Minority, New Republic, Jan. 3, 1994, at 12, 14. 
racial meaning of Hispanic as long as that racial definition has the capacity to differentiate between whites and non-whites. The ethnic category, which fails to do this, is threatening to race relations as they currently exist. Thus, I embrace the classification of Hispanics as an ethnic and social construction and reject the move to transform it to the racial and biological classification scheme which is driven and defined by phenotype and genotype. ${ }^{179}$ The treatment of Hispanics as an ethnic category supports the view that destabilizing the trademark of black and blackness will have a positive impact on race relations by diluting the distinctions between whites and blacks (and other minorities), ${ }^{180}$ thereby reducing racialism and racism. ${ }^{181}$

By contrast, as long as race is equated with ethnicity for African Americans, other than passing, ${ }^{182}$ which occurs on a very limited scale, African Americans cannot shed or transform their identity when it is to their advantage to do so, as do whites. African Americans, in contrast, have no choice but to remain the "other" and the different in this society.

\section{Ethnicity as a Unifying/Positive System of Categorization}

Ethnic categories, as I envision them, are based on a considerable number of factors, all of which are, in essence, socially constructed. ${ }^{183}$

179. Genotype refers to "the genetic constitution of an organism [or group of organisms]." TrRE AMERICAN HeR ITAGe DictionaRY 553 (2d College ed. 1985). For a further discussion of phenotype, see supra note 2 and accompanying text.

180. In order to employ any negative stereotypes associated or assigned to an individual because he or she is an Hispanic, that individual's ethnicity must be communicated to the individual assigning the stereotype, because, except on the margins-such as an individual wearing a serape or a sombrero, if I may employ a stereotype to make a point-the individual cannot be identified by phenotype or visibly as an Hispanic. Moreover, since that communication must be made in order for the identification to occur, it can also be masked or hidden to negate any negative consequences which fiow from such identification. In other words, the person with the power to control the consequences of ethnic identification is the person being classified ethnically, as he or she can choose to either convey his or her ethnic identity or mask same. Conversely, since racial identity is driven by phenotype and is visually observed, the person with the power to control or make the racial identification is the person making the classification rather than the person being classified, and there is little, if anything, the individual being classified can do to thwart attempts at classification and the ensuing consequences. The one exception to this latter paradigm is "passing," which occurs when a person who is black under the "one drop" rule but who is visibly white passes for white by masking his or her black heritage. For a discussion of passing, see supra notes 125-126 and accompanying text.

181. See infra Part III.C.

182. See supra notes 175,125 and accompanying text.

183. Ethnic categorics are similar to racial categories in that both include geographic origination. Nonetheless, the fact that one is born in a Latin American country and is therefore considered an Hispanic is still a social construct, because the identification and recognition of countries is socially constructed. Of course, one cannot avoid this social construct by changing the country of one's birth; nor can one be boru in multiple geographic locations. However, one can apply for a change of citizenship, perhaps weakening the importance of the location where one is bom and overcoming somewhat the social disadvantages of being bom in a certain location. For a further comparison of 
In this sense, ethnicity becomes a positive tool for categorization in that it allows an individual to volnntarily unite herself with others who share her background and belief systems. Once embraced, ethnicity provides a sense of culture not necessarily afforded by racial categories:

So important is the link between the concepts of ethnic group and culture that Barth calls an ethnic group a "culturebearing unit." Barth divides the culture contents of an ethnic group into two kinds: the overt signals or symbols of identity"cultural diacritica" such as langnage, religion, rituals, dress style, or dietary preferences that nnembers look for and exhibit to show identity-and the underlying values, codes of ethics, or standards of morality shared by group meinbers. ${ }^{184}$

As a result, ethnicity unites and empowers the members of the group, thus providing a sense of community.

Pierre van den Berghe goes even further to include the socio-biologists' emphasis of kin selection and reciprocal altruism in the nonhuman world by regarding ethnicity as "kin selection" and the ethnic group ("ethny") as representing the outer limits of that "inbred group of near or distant kinsmen whom one knows as intimates and whom therefore one can trust. One intuitively expects fellow ethnics to behave at least benevolently toward one because of kin selection, reinforced by reciprocity. The shared genes predispose toward beneficence; the daily interdependence reinforces that kin selection. Fellow ethnics are, in the deepest sense, 'our people.'" Ethnocentrism, the identification of ns, the insiders whom we trust and the discrimination against them, the outsiders, whom we distrust is an inherent feature of all ethnic groups. ${ }^{185}$

In this sense, ethnicity serves as the transmitter of values, culture and the internalization of societal norms. In addition, because differences among ethnic groups are visually indistinguishable, the fact

the factors that go into determinations of ethnicity as opposed to race, see supra notes 164-166 and accompanying text.

184. LANDA, supra note 170, at 16-17 (citing ETHNIC GrouPs AND BouNDARIES (Fredrik Barth ed., 1969)).

185. Id. at 17 (summarizing Pierre L. van den Berghe's observations in ThE ETHAIC Phenomenon (1981)). As Barth further notes:

[T] he ethnic boundary canalizes social life-it entails a frequently quite complex organization of behaviour and social relations. The identification of another person as a fellow member of an ethnic group implies a sharing of criteria for evaluation and judgement. It thus entails the assumption that the two are fundamentally "playing the same game".... On the other hand, a dichotomization of others as strangers, as members of another ethnic group, implies a recognition of limitations on shared understandings, differences in criteria for judgement of value and performance, and a restriction of interaction to sectors of assumed common understanding and mutual interest.

Fredrik Barth, Introduction to ETHNIC GRoups AND BouNDARIES 9, 15 (Fredrik Barth ed., 1969) (emphasis added). 
that one has an ethnic ancestor becomes something that is prized (as a source of pride concerning how far one has progressed or "come" in this society), rather than hidden. Having a Jewish/Italian/Irish/Lithuanian ancestor becomes a point of pride and distinction.

The lack of an African American ethnic category in American society has had drastic consequences for blacks. When coupled with "Color Consciousness," a lack of ethnicity impedes the formation of a positive community that is enriching and rewarding. Unlike whites, most African Americans, due to the legacy of slavery and the forced erasure of their ancestor's language, customs, oral history, etc., cannot trace their ancestry to a country of origin or a specific African tribe that would provide an ethnic identification. ${ }^{186}$ Indeed, even if an African American were able to trace his or her African ancestry back to a specific individual in a recognized tribe, ${ }^{187}$ that identification may have little meaning due to the forced and voluntary miscegenation that occurred (not only among white masters and black slaves but also among blacks from many different tribes who were indiscriminately thrown together) during and after slavery.

As a result, American blacks were denied the positive benefits of ethnicity and became locked into the forced, inflexible racial dichotomy. Blacks must move away from this dichotomy created by the combined effects of the "one drop" rule and color consciousness and embrace an ethnic identity. Ethnicity as a malleable and voluntary category provides a liberating tool which can be shed when necessary for protection of the individual and embraced when appropriate as a sense of identity. Under the ethnic paradigm, African Americans, as well as other minority groups, can embrace their ethnicity as a source of pride and unity. Self-identification can be transformed from a negative to a positive.

However, ethnic categories will not inaterialize unless the current racial classification scheme is destabilized. By recognizing multiple racial categories, it is hoped that the boundaries of racial identification will dissolve and that ethnic identity, with the positive attributes associated with it, will be recoguized as the primary paradigm by which to identify and classify individuals. Moving from the visual-racial identification to the learned-ethnic identification will have positive results, but not without the costs associated with the transition from a

186. For many African Americans, it is impossible to identify whether they come from East, West, or Central Africa, and whether their ancestors belong to any of the tribes, such as Pygmies, Mandigo, Ibo, etc., that populate Africa and from which many slaves were taken on the forced migration to the United States.

187. For an example of one allegedly successful attempt, see ALEX HALEY, Roots (1976). 
world in which all persons who are not white are categorized as African American or other. It is to those costs that I turn.

\section{B. The Short-Term Costs and Long-Term Gains of Destabilizing Racial Categories}

The transition from a biracial society, in which approximately ninety-four percent of the American population identified itself as black or white in the 1990 census, ${ }^{188}$ to a multi-level classification system, in which a multiplicity of races and ethnicities are recognized, will not be easy. Given this country's history of race relations (which is a somewhat oxymoronic concept considering that much of this country's racial history can be described as an absence of relations between whites and blacks), the transformation from a biracial to a multi-racial society will not happen quickly or effortlessly. Nor will it be without wellmeaning political opponents, such as the black politicians and commentators who currently reject the use of multi-racial categories and support the "one drop of blood" rule because they believe that change will reduce the political power of blacks. ${ }^{189}$

Indeed, in the short term, the implementation of multiple racial and ethnic categories may create confusion and regression in the area of minority political advancement. If race and racial categories are destabilized so that the mark of black and blackness become irrelevant, certain consequences will inevitably follow.

The objections to destabilizing the current racial classification system in favor of multi-racial and ethnic categories seem to be threefold. First, that it will significantly reduce the number of people who identify themselves as black and, as a result, weaken that group's political power. Second, that the adoption of multi-racial and ethnic categories will result in the fractionalization of the black community, pitting light against dark and dark against darker, ${ }^{190}$ thereby reinforcing the Color Consciousness that I have previously decried. ${ }^{191}$ Third and finally, that the use of multi-racial and ethnic categories will undermine any positive advancement in the current social system of racial

188. Rosin, supra note 178 , at 12.

189. See id. (commenting on the opposition by minority groups to a proposed trial run of a multiracial box on the 1996 U.S. Census).

190. 'For example,

when the U.S. Census Bureau announced this summer that they would include the multiracial box in a 1996 test run, minority groups revolted. The prospect that the new category would dilute their statistical strength had them clamoring in defense of the status quo. At a June hearing before the House Census Subcommittee, Billy Tidwell of the National Urban League went so far as to say a multiracial box, by splintering the black community between light-skinned and dark, would "tum the clock back on the well-being" of African Americans.

Id. at 12.

191. See supra notes 56-65 and accompanying text. 
classifications without providing an alternative structure for the furtherance of minority status based on an ethnicity regime. I address each of these arguments in turn.

First, although destabilizing the category of black and blackness will have the effect of splintering the black community, the alternative is even more problematic. Blacks, as currently defined, will soon become a "minority" minority, and will see their role as the predominant minority group pass to Hispanics. ${ }^{192}$ If current racial classifications continue to exist, blacks will soon lose their status as the predominant minority group but will still retain all of the negative baggage currently associated with the mark of blackness. If, however, race is treated as ethnicity, blacks, Anglo-Saxons, Germans, etc., and Hispanics are on relatively equal footing. ${ }^{193}$ In addition, blacks will benefit from all of the positive attributes of embracing a positive ethnic identity. When taking a long-term perspective, demographics, more than anything else, suggest that destabilization is the only viable strategy for blacks to rationally undertake.

Second, by destabilizing the tradeinarks of black and blackness, a credible argument could be made that, instead of combating racism and Color Consciousness, I am reintroducing it and einphasizing it within the black community through the express recognition of numerous mixed-race categories. Nothing, however, could be further from the truth. The reason for Color Consciousness is the existence of the white/black dichotomy discussed above. It is the entitlement of whiteness that causes soine blacks to be, as we used to say when I was an adolescent, "color-struck" so as to prefer lighter-hued, fine-featured blacks over darker-hued, less-Caucasoid-featured friends and acquaintances. Such Color Consciousness transforms blacks into intrinsic racists. ${ }^{194}$

The adoption of multi-racial categories is an essential step in the process of destabilizing the racial dichotomy that enables Color

192. Sam Roberts, Hispanic Population Outnumbers Blacks in Four Major Cities as Demographics Shift, N.Y. TMEs, Oct. 9, 1994, at 34 (noting that Hispanics are emerging as the nation's dominant minority).

193. See supra notes $49-50$ and accompanying text.

194.

[I]ntrinsic racists, on my definition, are people who differentiate morally between members of different races, because they believe that each race has a different moral status, quite independent of the moral characteristics entailed by its racial essence. Just as, for example, many people assume that the bare fact that they are biologically related to another persona brother, an aunt, a cousin-gives them a moral interest in that person, so an intrinsic racist holds that the bare fact of being of the same race is a reason for preferring one person to another. For an intrinsic racist, no amount of evidence that a member of another race is capable of great moral, intellectual, or cultural achievements, or has characteristics that, in members of one's own race, would make them admirable or attractive, offers any ground for treating that person as she would treat similarly endowed members of her own race.

APPIAH, supra note 2, at 14-15. 
Consciousness. However, these multi-racial categories are not an end unto themselves. Rather, they serve as a means by which we may debunk the white/black dichotomy and embrace an ethnic classification scheme based upon a positive shared identity of history and culture, in which race plays a small and arguably insignificant role.

When individuals of all minorities are able to affirmatively choose their group of association, many of the tensions between individuals who hold drastically divergent political beliefs, but are currently grouped together as "black," will diminish. Instead, minority groups will form positive ethnic bonds enabling them to identify as discrete powerful groups which may then band together as a coalition to fight against continued oppression. It is the white/black dichotomy, as currently implemented, that turns blacks against blacks in an effort to compete for limited resources and recognition within the white society. Unity is achieved between all blacks in recognizing that they belong to the same ethnic group-African American.

Third, an argument may be made that, by destabilizing the current racial classification scheme, minority groups will lose all entitlements currently designed to enable social advancement. For example, I take it as uncontroversial that if race is destabilized and reduced to a meaningless category, then those entitlements that turn on racial identification are subject to attack simply because the categories upon which they are based would no longer be recognizable. Thus, affirmative action, as currently constructed and operated, would be imperiled. Similarly, using race as an attribute to create voting districts would also no longer be plausible in a world with destabilized racial categories.

However, given the apparent demise of affirmative action and other race-based classifications, ${ }^{195}$ it is questionable whether race-based classifications will continue to afford blacks significant protections and entitlements. Given this political reality, minorities, and especially blacks, should embrace the destabilization of racial classifications as a positive development, even though a strong argnment can be made for such classifications in a world of affirmative action, race-conscious

195. See Adarand Constructors, Inc. v. Pena, 115 S. Ct. 2097 (1995) (applying strict scrutiny to affirmative action programs); Miller v. Johnson, 115 S. Ct. 2475 (1995) (limiting the use of racial gerrymandering); Missouri v. Jenkins, 115 S. C. 2038 (1995) (limiting remedy of desegregation of racially scgregated public school districts); see also William Claibome, Chipping at a Democratic Cornerstone: California Party Leaders Consider Compromise on Affirmative Action, WasH. PosT, Feb. 4, 1995, at A1; Kevin Johnson, Affirmative Action Next Target in California, USA TodAY, Jan. 11, 1995, at 1A; Joe Klein, The End of Affirmative Action, NEwswEek, Feb. 13, 1995, at 36-37 (discussing the California Civil Rights Initiative, scheduled as a ballot question in 1996, and remarking that "[a]ffirmative action is likely to end on Bill Clinton's watch"); R. Jeffrey Smith, GOP Senators Begin Studying Repeal of Affirmative Action, WASH. PosT, Feb. 6, 1995, at A1 (reporting that Senate Republicans are considering dropping affirmative action requirements in federal laws). 
gerrymandering, busing students to achieve school desegregation, and entitlement distribution along racial grounds. ${ }^{196}$

In a society that does not award entitlements or other benefits based on phenotype or racial identification, the costs of maintaining racial identification outweigh any positive benefits generated by the maintenance of such classifications. Indeed, in a world in which race is destabilized or deconstructed and ethnicity is allowed to flourish in the vacuum created by the obliteration of racial categorization, it is not all together clear that many of the "positive" attributes associated with racial identification that are prized by blacks cannot be maintained in a slightly different, yet more narrowly tailored, guise. Thus, although it seems implausible that any sort of racial or ethnic preferences will be employed in American society to award entitlements in the future, ${ }^{197}$ if such preferences are maintained and used, they are easier to defend if they are more narrowly tailored to benefit those who truly are in need of the preference. ${ }^{198}$

By that I mean, if race is deconstructed, and ethnicity replaces it as a viable method to categorize not only whites but blacks as well, there is still nothmg to preclude the distribution of entitlements based on ethnic identification rather than racial identification. Depending upon one's perspective, a cogent claim can be made that the first two centuries of this country's existence were largely devoted to creating and maintaining preferential treatment for the male inembers of one ethnic group: white Anglo-Saxon Protestants-to the exclusion of other ethnic groups such as Irish Catholics, Italian Americans, and Jewish Americans, as well as blacks.

196. Compare, for example, the argument maintaining that affirmative action in American society is valuable as a source of critique and revision of meritocratic evaluative and selection standards. See Susan Sturm \& Lani Guinier, The Future of Affirmative Action: Reclaiming the Innovative Ideal, 84 CALIF. L. REv. 953 (1996).

197. See supra note 195 and accompanying text.

198. Indeed, a common complaint against affirmative action is that, since it benefits any black irrespective of need, the policy is ill conceived: "Critics [of affirmative action] argue that most benefits go to educated, middle-income minorities. "It helps those who need it the least[.] For those in the inner city, it's at best useless and at worst creates a climate of hostihty from other workers." Bob Minzesheimer, Affirmative Action to Get Review from Republicans, USA ToDAY, Feb. 7, 1995, at 6A (quoting William Mellor, president of the Libertarian Institute for Justice).

Indeed, one of the leadiug proponents of this thesis, to perhaps which many of the objections to affirmative action can be traced, is Professor Stephen Carter of the Yale Law School. Professor Carter has written:

All the efforts at sceking to justify racial preferences as justice or compensation mask the simple truth that among those training for business and professional careers, the benefits of affirmative action fall to those least in need of them... . The structure of affirmative action programs in admission, and the predictable reaction to them by a rational university, offers a simple explanation: The most disadvantaged black people are not in a position to benefit from preferential admission.

CARTER, supra note 75 , at 72,80 (citation omitted). 
It takes no great leap to support a preference, if one is to be supported at all, that limits its beneficiaries to those who are not only phenotypically black, but also to those who are ethnically black (African American). ${ }^{199}$ Thus, affirmative action programs could be narrowly tailored to exclude impermissible beneficiaries (if that is the societal judgment) who, although phenotypically black, may be viewed as inauthentically or unethnically black. ${ }^{200}$ Similarly, just as there are voting districts which are identified with the ethnic group that comprises most of its members or residents, it also may be possible to construct in the future voting districts that are comprised almost exclusively of members of one ethnic group, like urban or inner-city blacks. ${ }^{201}$

Consequently, although it is possible that entitlements based on race or groupings based on racial identification may be either severely dimmished or completely negated in a world in which racial classifications are destabilized, that factor does not necessarily lead to a world in which neutrality, neutral principles, and process theory reign supreme. ${ }^{202}$ Nor does it lead to a world in which meritocracy and the application of merit are fairly and evenly applied in society to award entitlements. ${ }^{203}$ If it does, however, destabilizing race and racial identification eliminates the historical and societal costs and burdens associated with that dichotomous classification scheme while incurring no offsetting costs and burdens. If, on the other hand, racial or other classifications are maintained and prized, then moving to a world in which racial categories are deconstructed or destabilized is valuable because the ethnic categories and classifications promoted herein are more narrowly tailored to conform to the objectives which are sought via the classification.

199. For example, if it is determined that inner-city or urban blacks who bore the brunt of segregation and racism should reap the benefit of a preferential admissions or employment plan, certain proxies, such as socio-economic status, geographic location of residence, parents' degree of educational attainment, segregated or integrated high school and primary schools attended, etc., could be used to construct the ethnic category of urban or inner-city blacks. These blacks would then be differentiated from either rural blacks or those blacks who are not ethnically black because they have not experienced the shaping cultural forces of the African-American community or "nomos."

200. Elsewhere I have described what it means to be characterized as "inauthentically black." See Johnson, supra note 62, at 1628-29.

201. As Pam Karlan and Daryl Levinson have noted, the list of possible criteria for grouping voters under Equal Protection analysis includes religion and other "relatively stable traits." See Pamela S. Karlan \& Daryl J. Levinson, Why Voting is Different, 84 CaLIF. L. Rev. I201 (I996).

202. A neutral society devalues or ignores individual characteristics such as race and ethnicity, and focuses instead upon the construction and use of a neutral and fair process that awards entitlements consonant with principles of meritocracy. See Herbert Wechsler, Toward Neutral Principles of Constitutional Law, 73 HARv. L. Rev. I, 15 (1959). For a critique of the use of neutral principles in constitutional law, see Gary Peller, Neutral Principles in the 1950's, 21 U. Mrch. JL. REF. 56I, 566-67 (1988).

203. See Guinier \& Sturm, supra note 196. 
Thus, when analyzed from a long-term perspective, each of the objections to the adoption of multi-racial categories can be sufficiently rebutted. Failure to destabilize racial categories will have the effect of entrenching the long-term detrimental costs of a biracial classification scheme which serves to 1) foster divisions, distinctions, and differences, generally, and lead to racism, specifically, 2) create a historical badge of inferiority that is associated with being a minority, and especially a black minority, in this society, ${ }^{204}$ and 3 ) entrench the privileged property right in whiteness that whites use to subordinate blacks and others while elevating their own self-worth. ${ }^{205}$ In a society of continued racial oppression, ethnicity provides a positive classification scheme for minorities to embrace and utilize to achieve long-term political and social advancement.

\section{The Future: Building on the Past to Establish a Positive Ethnic Identification for African Americans}

What does the future look like in a society in which race is no longer a stable, viable factor by which individuals are classified? If the existence of multi-racial categories leads to a rise in ethnic identification and the use of ethnicity to categorize people instead of race, what does that portend for blacks who heretofore have been exclusively classified based on race? Can a positive ethnic identity arise to encapsulate those who previously were classified solely racially as blacks to constitute a new ethnic group that I have designated as African American? I am the first to admit that throughout I have been referring to ethnic groups and ethnicity as though they will rise like self-leavened dough among blacks once race is destabilized. That, of course, will not automatically happen, and I can only sketch here what might happen in a world in which race is minimized and ethnicity is prized.

First, and I must make this clear, although ethnicity presupposes shared history, language, culture, and values which are transmitted from one generation (and then incorporated) to the next generation, and so on, I make no claim that blacks will forge an ethnic group based solely on the fact that they are descendants of a people that were enslaved during a significant portion of American history. This would conflate race and ethnicity by ascribing to all blacks, wherever located and however situated, membership within the ethnic group and

204. Brown v. Board of Education, 347 U.S. 483, 494 (1954) (discussing the need for integration to remove the badges of inferiority created by slavery, and subsequently, de jure segregation of schools).

205. For a discussion of the property right in whiteness and how it affects matters such as residential housing patterns, see Johnson, supra note 62 , at $1605-16$. 
concomitantly set its boundaries so as to exclude-anyone who is not black. Ergo, race becomes ethnicity and ethnicity becomes race.

If the only thing the ethnic group shares is a history of slavery, the color of skin and a conception of being treated as "other" in American society, then that ethnicity would not be based on shared values, norms, culture, language, etc., but based on the group's [mis]treatment by the dominant group in American society. These do not represent positive attributes or values upon which to base ethnicity, but negative factors from which blacks have sought to escape rather than embrace.

Hence, my focus on ethnicity begins with the institution of slavery on blacks, but does not end there. Slavery can be said to be the vehicle which gave birth to the African Ainerican ethnic group, but it cannot be said to be the only significant factor that shaped and constituted the group. ${ }^{205}$ Other factors have also played a role in creating the African American ethnic group.

It is interesting to note, as soine have contended, that blacks were the first group in recorded history to voluntarily remain in the country in which they were enslaved. ${ }^{207}$ How did that come about and why is that important? The answer to the first question is beyond the scope of this Article, but two initial thoughts come to mind. First, repatriation to the country of ancestry or origin was practically impossible given the years that separated enslavement and freedom, and given the eradication of slave culture which eliminated vestiges of country of origin and ancestral heritage. Second, and just as importantly, inany freed slaves and descendants, due to the level of miscegenation that occurred while enslaved and after, ${ }^{208}$ no doubt felt more unwelcome in their ancestral

206. The influence of slavery in creating an ethnic group should not be minimized. Perhaps the most prominent example of an ethnic group defined and united by persecution are Jews. My colleague, Pam Karlan, when asked why Jews are more recognizable as an ethnic group when compared to other religious groups (e.g., Calvinists, Southem Baptists, Roman Catholics, etc.) posited many reasons, but the primary reason was a shared history of enslavement and religious persecution. See also Paul Berman, Introduction: The Other and the Almost the Same, in BLACKs AND JEws: Alliances and ARguments 14 (Paul Berman ed., 1994) (drawing an analogy between slavery and Nazism).

207. See, e.g., Giovanni, supra note 6, at 124 .

208. The notion that miscegenation occurred primarily between slave masters and slaves on the plantation and was always involuntary from the slave woman's perspective is belied by historical evidence:

Perhaps the most striking indication of the erosion of racial lines in urban settings was the mucli higher proportion of mulatto babies born to black women in antebellum Southem cities, as compared to black women on plantations. An estimated 1 to 2 percent of the babies bom to plantation slave women were fathered by white men, compared to nearly half in the cities. Southem cities of that era had a chronic surplus of white men over white women and a chronic surplus of black women over black men. Similar sexual imbalances have led to mixed offspring in many other times and societies, so the antebellum South was not exceptional in this. If most of the slave women who gave birth to racially mixed babies were sinply raped by their owners, then such babies would undoubtedly have been more 
lands (if discoverable) than in America, the "Great Melting Pot," whose democratic ideals they embraced. The fact that blacks chose to remain in America after emancipation is an important factor in defining their ethnic group.

I assume separatism and the creation of a new ethnic group based on factors other than racial identification will not develop as'long as racial identification remains stable and predominant. Therefore, I choose to destabilize the racial classifications upon which identification and the failed strategy of integration are based. ${ }^{209}$ This, in turn, will allow ethnicity to flourish.

Perhaps it would be possible to construct a traditional sort of ethnicity and ethnic group among individuals who are racially identified as blacks by focusing on their shared culture. On the other hand, to say that inner-city or urban blacks who have their own language and norms share a similar culture and norms with rural sharecropping blacks who inhabit the Mississippi Delta is too great a reach. Although they lack a shared language and he horizon, I contend it is possible to create an ethnic group consisting of these two disparate groups, as well as others, which is based upon factors other than language, hifestyle, or grosser morphology.

However, I focus on the larger picture. Blacks, even though they clearly occupied a subordinate position in the racial hierarchy in American society, chose to stay because they not only embraced American democratic ideals, but because they also believed most fervidly that their role was and is to ensure that society achieves the goals embraced by those ideals. ${ }^{210}$ Significantly, they also believed and

common on the plantations, where white control was greatest, rather than in the cities, where it was more lax.

SOWELL, supra note 60 , at 207 (citations omitted).

209. Indeed, my contention is that "integration" and its corresponding societal costs are based on racial, not ethnic, differences, and that destabilization of racial classifications will effectively bring ethnic groups together without the need for an integration strategy.

210. As Nikki Giovanni notes,

1 have contemplated what life must have been like around 1865 or when freedom [for black slaves] became a possibility. Why didn't we seek boats to take us to Haiti, which was already a free, black republic? Why didn't we start great treks, not just a few wagon trains here and there, to the uncharted lands of this nation? What made us determined to fight it out essentially where we were? Some books tell us we loved enslavement-we didn't have to worry about our care or our duties. Some books say we didn't know where to go. Some books tell us we believed the promises of Emancipation that we would be given forty acres and a mule. Mostly I think it was cosmic. The spirituals show us a people willing to "wait on the Lord." ... We were chosen to be witnesses. . . America may not be the best nation on earth, but it has conceived loftier ideals and dreamed higher dreams than any other nation. America is a heterogeneous nation of many different peoples of different races, rehigions, and creeds. Should this experiment go forth and prosper, we will have offered humans a new way to look at life; should it fail, we will simply go the way of all failed civilizations. The spirituals teach us that the problem of the twentieth century is not the problem of the color line. The problem of the twentieth century is the problem of civilizing white people. 
believe as a group that the sacrifices that they have made for the creation of this society constitute an investment that eventually must pay off.

Therefore, to a large degree, the ethnic group that consists of African American begins with slavery but transcends slavery. This group, indigenous to the United States, ${ }^{211}$ should be viewed as the group which holds the mirror to American society so that American society can judge whether it has indeed met or achieved its ideals and promise. ${ }^{212}$ African Americans represent the Excluded Tribe, the group thus far excluded from fulfilling its dreams and, in the process, the American dream. It is their struggle to achieve that dream that forms the basis for the ethnic identification that is African American.

African Americans as the Excluded Tribe derive their ethnic existence from their position as excluded and "other" in American society. It is that otherness that constitutes the African American identity. Being treated as other is the bond that unifies African Americans and serves as the impetus to the developinent of a unique "nomos" for the African Ainerican community. ${ }^{213}$ African Americans grow up, develop, and become citizens in a society in which they incorporate language, values, and a shared history that marks them as "other" and that teaches them to react accordingly.

African Americans, like members of other ethnic groups, derive two primary benefits from their membership in their unique ethnic group: "distinctiveness" and "separateness." Moreover, membership in an ethnic group, like one's racial identity, is not chosen voluntarily. One is born into an ethnic group and can only change that membership with difficulty. ${ }^{214}$

African Americans share a burden and a hope that is unique to them and connects them to all other African Americans. That burden is obvious: it is the separateness and the discrimination that creates the

Giovanni, supra note 6, at 124-25.

211. As I have argued previously:

[T]he African-American community is unique in American society because of the historical forces that shaped it. African-Americans-like Native Americans-can claim that they have their own culture, language, and religions, each a product of their subordinated position in American society. African-Americans, however, have no geographic lands to call their own, nor any claim that their unique culture existed prior to and independently of majoritarian culture. Nonetheless, the absence of those factors is not dispositive of my claim that the presence of an African-American culture, language, and religion siguifies the existence of a separate community, the "nation within the nation" claimed by African-American nationalists.

Johnson, supra note 22, at 1415 (citations omitted) (emphasis added).

212. See also Giovanni, supra note 6, at 122 (stating that by "remain[ing] a black American[, the author] force[s] all others to become and claim their other Americanisms").

213. See supra notes 22-23 and accompanying text for a definition and discussion of "nomos."

214. Johnson, supra note 22, at 1415 (quoting Jennifer Roback, Plural But Equal: Group Identity and Voluntary Identification, Soc. PHIL. \& PoL'Y, Spring 1991, at 60, 60). 
otherness. The hope is more difficult to articulate. At its base, the hope represents an attempt to achieve equality and oneness with the group that views them as others. That hope binds the group together as a cohesive glue. This sense of hope is what I believe African Americans feel when they see and take pride in the success of another African American. Conversely, it is the sense of sadness and empathy that African Americans feel when they hear the alarming statistics of black incarceration, teen pregnancy rates, and other negative statistics that reflect their plight as "other."215 African Americans feel either happiness or sadness, pride or shame, because they know the pressures, the hurdles, the fear, and other emotions experienced by those who share the experience of other.

Does this mean that all blacks are African Americans? Definitely not! Those individuals who are racially identified as black, but feel no sense of otherness, no sense of exclusion or identification with others similarly excluded and made to feel different or other, are not African American. These black individuals have been fully assimilated into American society and have lost their ethnicity just as a fourth or fifth generation Irish, Italian, German, or Polish person, who has not maintained her ties to her homeland or community, has lost her ethnicity. I can name names or point out those whom I believe are not African Americans, but $I$ think it is more productive to point out that there is no political litmus or other test to determine who is African American and who is not. As with ethnicity, it is a matter of self-identity and choice. Thus, I have no quarrel with anyone who would contend that Justice Clarence Thomas is an African American, notwithstanding his contrary political position and judicial philosophy. Similarly, Reverend Jesse Jackson is clearly an African American, given his life horizon and experiences.

The bottom line, however, is not whether the individual believes himself or herself to be a member of the ethnic group consisting of African Americans or any other ethnic group. Ethnic boundaries not only "canalize[] social life;"216 rather, these boundaries are fluid, evolving, and self-enforcing to a significant extent. The African American ethnic group will determine both its membership and those who should be excluded from its membership for violating or not observing its norms. Self-proclamation is not enough. Suffice it to say, I believe that $I$, too, am an African American. I hope the other African Americans concur.

215. For a statistical recitation of the dismal plight of American blacks in American society, see Johnson, supra note 141, at 1046-54.

216. See Barth, supra note 185 , at 15. 


\section{CONCLUSION}

To paraphrase Cornel West, race, unfortunately, continues to matter in American society. ${ }^{217}$ The biracial categorization of race is a relic of an antebellum system of slavery that should have been discarded long ago, when slavery itself was abolished. However, the dichotomous classification of race has been remforced in American society for over three centuries. This biracial categorization continues to serve the same role that it did in slavery - to mark and define those who are part of the dominant, privileged class while branding those who are subordinate and on the bottom. As long as this biracial marking continues to occur, progress in race relations will be impeded.

Many have lost sight of the fact that the second most important judicial decision for blacks, Loving $v$. Virginia, ${ }^{218}$ which invalidated miscegenation laws, was intended to destabilize racial classification, in that the primary purpose of anti-miscegenation laws, which only criminalized interracial marriages involving a white participant, was to maintain the dominance and purity of the white race and preclude the destabilization of racial categories. ${ }^{219}$ This Article, then, picks up where Loving leaves off and contends that miscegenation alone will not destabilize racial categories. Rather, by expressly destabilizing racial categories, the very notion of mixing (miscegenation) will be made irrelevant or, at the very least, less relevant.

By drawing upon lessons learned from trademark law, I have contended that the exclusivity of the two marks of "white" and "black" should be deconstructed and destroyed. In their place, I contend we should create a society in which multi-racial categories are encouraged and recognized. That, hopefully, will diminish the importance of race in our society and allow ethnicity to flourish as a positive classification scheme. Ethnicity, which allows for assimilation, is a useful tool for categorizing and differentiating between others. The form of essentialization ${ }^{220}$ provided by ethnic identification is still

217. CORNEL West, RACE Matters (1993).

218. 388 U.S. 1 (1967).

219. For an analysis of Loving v. Virginia, see Karst, supra note 154, at 292.

220. See Angela P. Harris, Race and Essentialism in Feminist Legal Theory, 42 STAN. L. REv. 581, 585-86 (1990) (discussing essentialism and the dangers of attributing the "essence" of the majority to other minority groups, such as attributing the experience of "women" in general to black women in particular). Harris concludes that without essentialism or categorizations we are placed in a world like that of "Ireneo Funes" (a literary character described in Harris' article) in which everything is unique and no generalizations can take place; however, the categories must be explicit and carefully defined so as to represent the true experiences of the groups being categorized. Id. 
necessary and valuable given the stage of development of this country and its history of race relations. ${ }^{221}$

The "advantage" that ethnicity has over race is that one's disclosure of ethnicity is a voluntary act over which the individual has control. An individual can choose to expose her ethnicity in order to reap its benefits or, if revealing ethnicity is deemed worthwhile for some other reason, to incur the costs. The key is in the choice, a choice that does not exist with regard to the disclosure of one's racial identity as that is constructed in this society.

Of course, nested within the ethnic categorization of African American are a plethora of people of all races, that is, blacks, mestizos, mulattos, and, surprisingly, whites. ${ }^{222}$ In a world in which African American is embraced as an ethnic designation, race continues to exist as a vehicle to classify individuals, but it is recognized as a social construct with fluid boundaries and limited constraints. Given the way that individuals first classify other individuals (strangers), it would be

221. Given this country's history as a "melting pot," and the role that emigration from other countries has played in its development, it is unrealistic to assume that national, ethnic, and other differences will not continue to be recognized and valued.

222. It is only logical that those who would be classified racially as white by their phenotype could instead identify themselves ethnically as African American. Under the current racial classifications governed by the "one drop of blood" mle, an individual who is $98 \%$ white and $2 \%$ black would be classified as black but could likely pass for white if her physical manifestations allowed her to do so. Thus, racial categories, as applied to this individual, are highly indeterminate. Under my proposed scheme of ethnic classifications, this individual could classify herself as African American if she has chosen to live in and remain as part of the African American community, embracing its norms and cultnre. Glenn Loury details the complications such an individual would face attempting to "reverse-pass" for "black" under the cnrrent racial dichotomy:

Despite this zeal, it took courage for Woody to attend [a political rally on the South Side of Chicagol. Though he often proclaimed his blackness, and though he had a Negro grandparent on each side of his family, he nevertheless looked to all the world like your typical white boy. Everyone, on first meeting him, assumed as much. I did, too, when we began to play together nearly a decade earlier, jnst after I had moved into the middle-class neighborhood called Park Manor, where Woody's family had been living for some time.

....

It dawned on me...that Woody's parents must have been passing for white in preintegration Park Manor. The neighborhood's changing racial composition had confronted them with a moment of trnth. They had elected to stay and raise their children among "their own kind." This was a fatefnl decision for Woody, who, as he matured, became determined not simply to live among blacks but, perhaps in atonement for his parents' sins, unambiguously to become one. The young men in the neighborhood did not make this easy. Many delighted in picking fights with him, teasing him about being a "white boy," and refusing to credit his insistent, often repeated claim: "I'm a brother, tool"

....

I recall this story about Woody because his dilemma, and mine, tell us something important about race and personal identity in American society. His situation was made so difficult by the fact that he embraced a self-definition dramatically inconsistent with the identity refiexively and stubbornly imputed to him by others.

Glenn C. Loury, Free at Last? A Personal Perspective on Race and Identity in America, in LURE AND

LOATHING, supra note 6 , at $1,2-4$. 
naive to believe that racial classification would disappear. ${ }^{223}$ However, destabilizing race through lessons learned from trademark law and promoting ethnicity, which is learned and transmitted through a dialogue or exchange of information (some visual, some not) rather than intuitively visualized and recognized, diminishes the import of racial classification and the harms it creates.

Unfortunately, destabilizing the current racial classification scheme may have the short-term effect of reducing the political strengths of the currently constructed racial groups and creating a society in which racial categories soon become irrelevant. ${ }^{224}$ A world without race, or at least without a biracial conception of race, is frightening to some and rightfully so. The unknown always represents a challenge.

A world in which dichotomous, biracial categories do not exist is, however, feasible. As I conceive of it, race and racial identity will be treated, to some degree, like ethnicity. American society consists of numerous ethnic groups who interact with each other on a daily basis, creating little friction in the process. Ethnic groups have a shared history and past. They simultaneously share and create a "nomos" or community that is defining and constitutive of the individual's identity. This nomos is, therefore, enriching and worthy. ${ }^{225}$ Consequently, African Americans can be said to comprise an ethnic group that shares a common history and past that is not based solely or even predominantly on skin color, although it is a product of their treatment in American society as a result of skin color. That recognition of ethnicity, however, is quite distinct from a society that has created and maintains a biracial dichotomy which serves to subordinate one group based solely on the color of one's skin.

If racial categorization remains viable, the societal goal should be to achieve a multiplicity of categories so that, in the short-term, the existing harmful stereotypes are lessened, and, in the long-term, they become meaningless. In addition, the demise of binary racial identity should allow ethnic identity to flourish in its vacuum. The first step is destabalization and the destruction of the dichotimization of races that has been created and maintained to benefit whites at a cost to blacks.

This first step is part of a larger debate over the efficacy of multiculturalism and what it means for black people. Indeed, it has

223. See, e.g., Fiske, supra note 98 , at 166.

224.

Though a multiracial category seems to make racial accounting more accurate, Census statisticians claim it is too broad to be useful. "Who"s in there? You could fit all of the U.S. in that category," says Juanita Tamaya Lott, a Census consultant. "In order to do statistical analysis we have to have mutually exclusive categories."

Rosin, supra note 178, at 14.

225. Johnson, supra note 22, at 1419-20. 
been alleged that there is a "postmodern conspiracy to explode racial identity" and that this conspiracy will ultimately be harmful to African Americans. ${ }^{226}$ That, however, is not the purpose of this Article. As expressed succinctly by Patricia Hill Collins:

[The] claim that intellectuals implicated in the postmodern conspiracy want to "explode racial identity" as we know it leads to the second significant question raised by his essay, namely the issue of an essential Black identity as the foundation for Black political practice. In brief, I think that there is a difference between thinkers who aim to explode racial identity in order to further their own careers, (Shelby Steele and Clarence Thomas come to mind), and thinkers who wish to explode racial identity as we know it, in order to develop political practice more suitable to address the racism that Black people face today. ${ }^{227}$

The purpose of this Article was and is to develop an ethnic identity more suitable to combating the racism that is endemic in current American society.

226. Jon M. Spencer, Trends of Opposition to Multiculturalism, BLACK SCHOLAR, Spring 1993, at 2.

227. Patricia H. Collins, Setting Our Own Agenda, BlaCK ScholaR, Summer/Fall 1993, at 52, 53 (responding to Spencer, supra note 226). 